\title{
Integrating animal temperament within ecology and evolution
}

\author{
Denis Réale $^{1 *}$, Simon M. Reader ${ }^{2,3}$, Daniel Sol ${ }^{3,4}$, Peter T. McDougall ${ }^{3}$ and \\ Niels J. Dingemanse ${ }^{5}$ \\ ${ }^{1}$ Canada Research Chair in Behavioural Ecology and Groupe de Recherche en Ecologie Comportementale et Animale, Département des Sciences \\ Biologiques, Université du Québec à Montréal, CP-8888, Succursale Centre-ville, Montréal, Québec, H3C 3P8, Canada \\ ${ }^{2}$ University of Utrecht, Behavioural Biology and Helmholtz Institute, Padualaan 8, PO Box 80086, 3508 TB Utrecht, The Netherlands \\ ${ }^{3}$ Department of Biology, McGill University, 1205 Dr. Penfield Ave., Montréal, Québec, H3A 1B1, Canada \\ ${ }^{4}$ CREAF, Center for Ecological Research and Applied Forestries, Universitat Autònoma de Barcelona, E-08193 Bellaterra, Catalonia, Spain \\ ${ }^{5}$ Animal Ecology Group, Centre for Evolutionary and Ecologicial Studies, and Department of Behavioural Biology, Centre for Behaviour and \\ Neurosciences, University of Groningen, PO Box 14, 9750 AA Haren, The Netherlands
}

(Received 5 October 2005; revised 26 January 2007; accepted 30 January 2007)

\begin{abstract}
Temperament describes the idea that individual behavioural differences are repeatable over time and across situations. This common phenomenon covers numerous traits, such as aggressiveness, avoidance of novelty, willingness to take risks, exploration, and sociality. The study of temperament is central to animal psychology, behavioural genetics, pharmacology, and animal husbandry, but relatively few studies have examined the ecology and evolution of temperament traits. This situation is surprising, given that temperament is likely to exert an important influence on many aspects of animal ecology and evolution, and that individual variation in temperament appears to be pervasive amongst animal species. Possible explanations for this neglect of temperament include a perceived irrelevance, an insufficient understanding of the link between temperament traits and fitness, and a lack of coherence in terminology with similar traits often given different names, or different traits given the same name. We propose that temperament can and should be studied within an evolutionary ecology framework and provide a terminology that could be used as a working tool for ecological studies of temperament. Our terminology includes five major temperament trait categories: shyness-boldness, explorationavoidance, activity, sociability and aggressiveness. This terminology does not make inferences regarding underlying dispositions or psychological processes, which may have restrained ecologists and evolutionary biologists from working on these traits. We present extensive literature reviews that demonstrate that temperament traits are heritable, and linked to fitness and to several other traits of importance to ecology and evolution. Furthermore, we describe ecologically relevant measurement methods and point to several ecological and evolutionary topics that would benefit from considering temperament, such as phenotypic plasticity, conservation biology, population sampling, and invasion biology.
\end{abstract}

Key words: temperament, personality, individual differences, behavioural syndromes, coping styles, contextspecificity, shyness-boldness, exploration, aggressiveness, sociability.

\section{CONTENTS}

I. Introduction

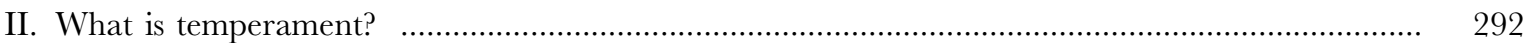

(1) Behavioural trait concepts in an ecological and evolutionary context f................................... 293

(2) Terminology for ecologists

\footnotetext{
*Address for correspondence: E-mail: reale.denis@uqam.ca
} 
(3) Properties of temperament traits _..................................................................................... 296

III. Why have ecologists and evolutionary biologists neglected temperament? …………………...... 296

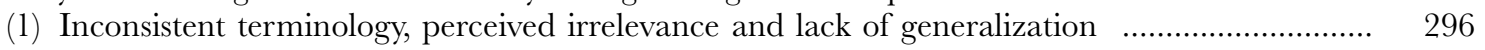

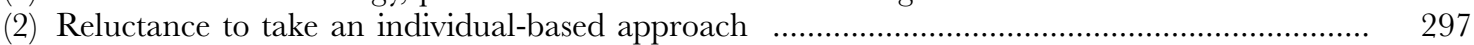

(3) The lack of a general framework ……………............................................................... 297

(4) Evidence for the ecological importance of temperament ……….......................................... 297

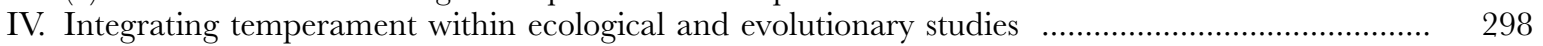

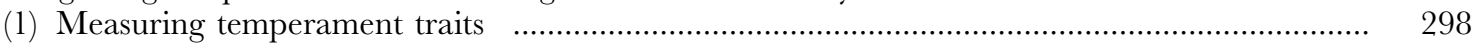

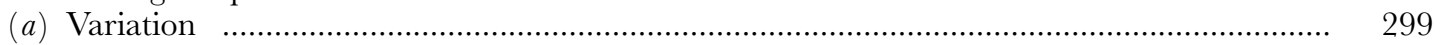

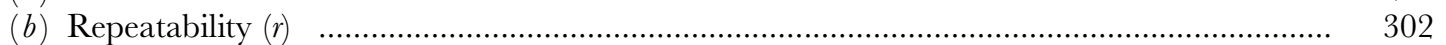

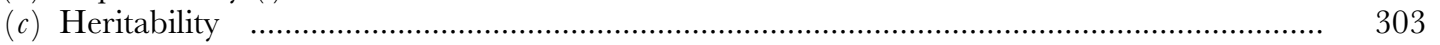

(2) Validating measures of temperaments traits ………........................................................... 304

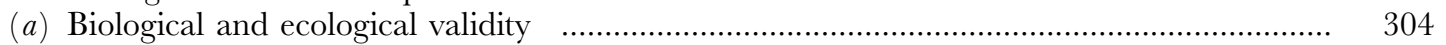

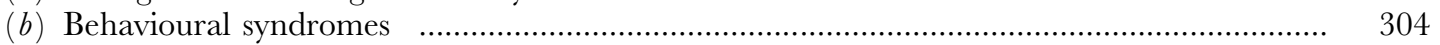

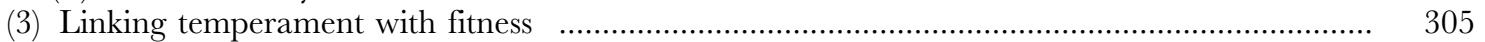

(a) Measuring selection ………..................................................................................... 308

(b) Adaptive explanations for the maintenance of variance in temperament traits ................ 308

(4) Temperament traits as adaptation: comparative studies ……............................................. 309

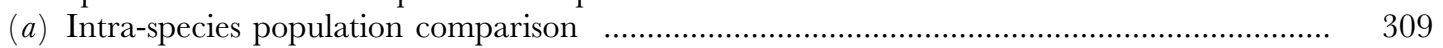

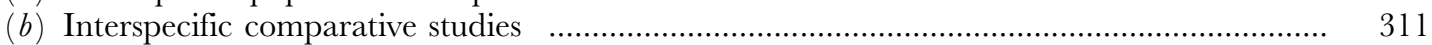

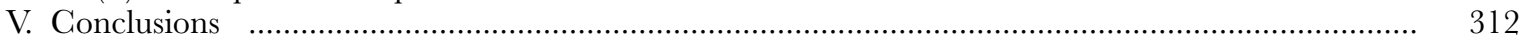

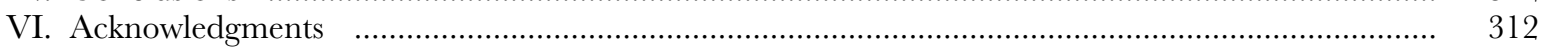

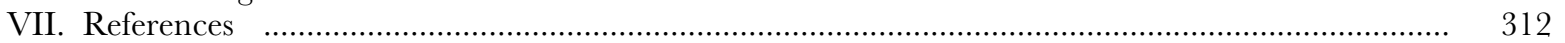

\section{INTRODUGTION}

How and for what reasons individuals - animals or humans differ in the way they react to potential risks, handle novelty, or interact with conspecifics, are questions that fascinate scientists and the general public alike. The study of temperament (or personality) differences has proven utility at many levels of society: from improvements in animal production, welfare, and conservation, to pharmacology, and, in humans, to prediction of disease risk, job satisfaction, risk-taking behaviour, and reaction to social stress (Boissy \& Bouissou, 1995; Le Neindre, Boivin \& Boissy, 1996; Caspi et al., 1997; Grandin, 1998; Martin, 1998; Carlstead, Mellen \& Kleiman, 1999; Trut, 1999; Malmkvist \& Hansen, 2001; Boissy et al., 2005; Boyce \& Ellis, 2005; Ellis, Jackson \& Boyce, 2006; McDougall et al., 2006).

Psychologists have long been interested in the study of human and animal temperament, which has led to significant theoretical and empirical developments (Wilson, 1994; Gosling, 2001; Boyce \& Ellis, 2005). By contrast, ecologists and evolutionary biologists have generally shown little interest in the concept of temperament, although certain temperament traits perceived to affect fitness directly, such as aggressiveness and reaction to predators, have received substantial scientific attention (Clark \& Ehlinger, 1987; Huntingford, Wright \& Tierney, 1994; Wilson et al., 1994; Boissy, 1995; Clarke \& Boinski, 1995; Greenberg \& Mettke-Hofmann, 2001; Sih, Bell \& Johnson, 2004a; Sih et al., 2004b; Ellis et al., 2006). In recent years temperament has begun to receive theoretical and empirical attention from ecologists (Wilson et al., 1994; Clarke \& Boinski, 1995; Greenberg \& Mettke-Hofmann, 2001; Sih et al., 2004a, b; Dall, Houston \& McNamara, 2004). However, ecologists generally do not perceive temperament as an important addition to our understanding of the ecology and evolution of animals. This is surprising given a growing body of evidence showing that temperament traits affect important ecological processes such as niche expansion, dispersal or social organisation.

The reasons why temperament has not yet been integrated into ecological theory are diverse, and include difficulties in definition, in finding appropriate methods to quantify temperament, and in testing the significance of these traits in the field. Our goal here is to build a supporting conceptual and methodological framework for the ecological study of temperament that may help overcome these difficulties. Moreover, we review extensive evidence for the genetic basis of temperament traits and links between temperament and traits of importance to evolutionary ecology, such as reproductive rate and survival. Obviously, many important questions regarding temperament remain to be resolved before developing a general framework. Nevertheless, we hope that the proposed framework will serve to guide and encourage future research in the field.

\section{WHAT IS TEMPERAMENT?}

A necessary first step is to define temperament traits in terms relevant to evolutionary ecology. Defining temperament traits, like traits in general, is not trivial (Wagner, 2001). We discuss the concept of a trait in an ecological and evolutionary context and extend this concept to provide a terminology for temperament traits. 


\section{(1) Behavioural trait concepts in an ecological and evolutionary context}

A character (or trait) can be considered as a characteristic of an organism shared by all or some of the individuals of a species that can vary, although not necessarily, among these individuals (we consider character and trait as synonyms; see Wagner, 2001, on the diversity of the character concept). Measured individual values for that character are called phenotypes. A quantitative genetic framework can provide a biological definition of a trait. Quantitative genetic models, which have received some recent support, assume that the variance of phenotypic quantitative traits (i.e., the trait measured) is influenced by a relatively large number of genes, each with small individual effects, and by a series of environmental effects (Falconer \& Mackay, 1996; Lynch \& Walsh, 1998; Roff, 1997; Flint, 2003; Reif \& Lesch, 2003). An important aspect of our definition is that two traits can be associated at the phenotypic level, illustrating their potential genetic or epigenetic links (Henderson, 1990; Wagner, 1996; Cheverud, 1996; Sih et al., 2004b).

Fig. 1 shows a conceptual model of the organisation of behavioural traits derived from Henderson (1990) and Wagner (1996). The goal of this model is to illustrate the hierarchical structure of traits within an organism rather than to describe the precise physiological and developmental machinery underlying the expression of those traits. Hence it does not include developmental feedback effects occurring at different levels or environmental effects. F1 and F2 represent two different biological functions of an animal species, such as anti-predator defence and mating. Behavioural traits (Bs; note that they could be other trait categories like life-history or morphological traits) involved in each function are not directly influenced by genes, but result from a complex network of neurophysiological and structural traits themselves a result of the indirect effects of genes (see Johnston \& Edwards, 2002). Phenotypic variation of a trait $\mathrm{B}$ results from both amongindividual allelic variability at loci with additive and nonadditive (e.g., dominance, epistasis) genetic effects, and from environmental variation (Falconer \& MacKay, 1996; Roff, 1997; Lynch \& Walsh, 1998). An important property of this model is that phenotypic variation of a composite trait (e.g., B) will depend on the cumulative and interactive genetic and environmental effects on the variation at an underlying level. Note that to simplify we limited the number of levels to a minimum; a behavioural trait not shown here could integrate several traits at underlying level B. For example, maternal behaviour in a mammal is composed of many other behavioural traits (e.g., nursing, nest building, grooming, vigilance and defence against predators). Therefore, the measure of a trait at one level, to some extent, also represents other traits that are genetically, developmentally and functionally related to the studied trait. For instance, B1 and N1 in Fig. 1 can be considered genetically the same trait since the same genes influence them, regardless of the fact they are phenotypically different: one trait is a behaviour pattern, the other a hormone concentration.

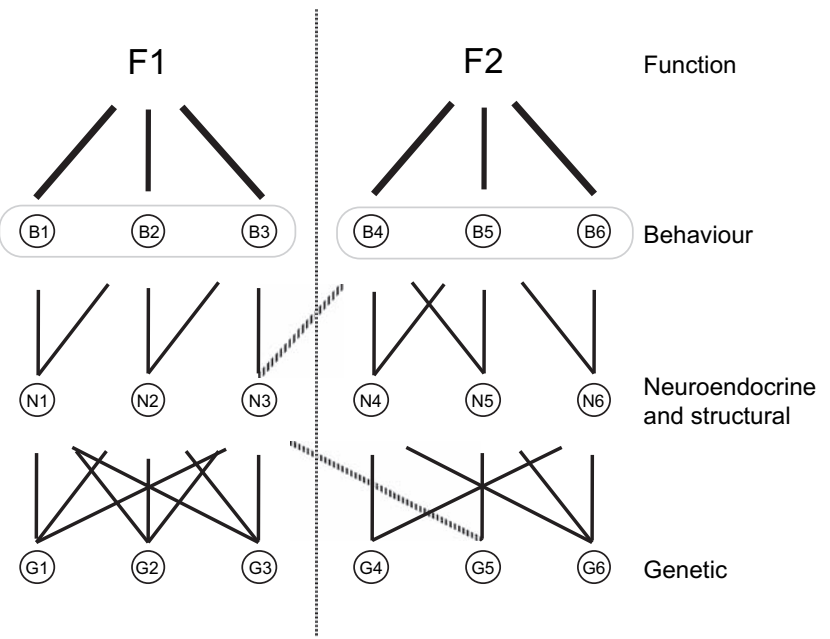

Fig. 1. Conceptual model of the organisation of behavioural traits. F1 and F2 represent two different biological functions. The second level is composed of behavioural traits (Bs) involved in each function. The next level is composed of neurophysiological (Ns; e.g., hormones, neurotransmitters, neuromodulators) and structural (e.g., neuronal structures, muscle characteristics) traits involved in each behavioural trait. The final level is composed of genes (Gs) that are involved in each neuro-physiological trait. For simplicity we do not show environmental effects, interactions among traits within each level, and feedback effects. We also do not include the developmental dimension of behavioural trait construction (see text). The traits $\mathrm{B} 1$ and N1 share exactly the same genes, and the genetic correlation estimated between these traits is 1 (Falconer \& MacKay, 1996; Roff, 1997; Lynch \& Walsh, 1998). Because of environmental effects, the phenotypic correlation should be lower, but still strong and significant. In that case, we could say that these two traits are part of the same behavioural syndrome (Sih et al., 2004b) and are two facets of a coping style (Koolhaas et al., 1999). Similarly, trait N1 and N2 show a genetic correlation of $1 . \mathrm{B} 1$ and B3 will be genetically correlated, although to a lesser extent, because some genes influencing B3 (e.g., G5 through N3) do not influence B1. Finally, B1 and B6 belong to two different genes-neurophysiology-behaviour pathways and will therefore show a null genetic correlation. This model could be extended to one function studied in two different environments within the same context (e.g., antipredator defence in $\mathrm{F} 1=$ high-risk and $\mathrm{F} 2=$ low-risk environment), at different ages (e.g., anti-predator defence in $\mathrm{F} 1=$ juvenile and F2 = adult), in the two sexes (e.g., mating behaviour in $\mathrm{F} 1=$ males and F2 $=$ females). For instance, some genes influencing a behaviour expressed in a high-risk environment may not influence the behaviour expressed in a low-risk environment. This means that two measures of the same phenotypic trait (i.e., antipredator defence) can be considered as two genetically different traits (Falconer \& MacKay 1996).

\section{(2) Terminology for ecologists}

Table 1 lists several published definitions of temperament and personality. The distinction between temperament and personality is often vague, but temperament frequently has 
Table 1. A non-exhaustive list of definitions of temperament, personality and coping style

\begin{tabular}{|c|c|}
\hline Definition & Source \\
\hline $\begin{array}{l}\text { Temperament: a person's or animal's nature, especially as it permanently affects their } \\
\text { behaviour. Personality: the combination of characteristics or qualities that form an } \\
\text { individual's distinctive character. }\end{array}$ & The Oxford English Dictionary (2005) \\
\hline $\begin{array}{l}\text { Temperament: relatively consistent, basic dispositions inherent in the person that } \\
\text { underlie and modulate the expression of activity, reactivity, emotionality, and } \\
\text { sociability. }\end{array}$ & Buss et al. (1987) \\
\hline $\begin{array}{l}\text { Temperament: the characteristic phenomena of an individual's emotional nature, } \\
\text { including his susceptibility to emotional stimulation, his customary strength and } \\
\text { speed of response, the quality of his prevailing mood, and all peculiarities of } \\
\text { fluctuation and intensity of mood; these phenomena being regarded as dependent on } \\
\text { constitutional makeup and therefore largely hereditary in origin. }\end{array}$ & Allport (1937), p. 54 \\
\hline $\begin{array}{l}\text { In addition to the notion that temperament reflects biologically based individual } \\
\text { differences in emotional responding, modern temperament theories also incorporate } \\
\text { Allport's idea that these biological differences are innate and form the foundation } \\
\text { upon which mature personality develops. }\end{array}$ & Clark \& Wilson (1999), p. 400 \\
\hline $\begin{array}{l}\text { Personality: those characteristics of individuals that describe and account for consistent } \\
\text { patterns in feeling, thinking and behaving. Temperament: in human research... the } \\
\text { inherited, early appearing tendencies that continue throughout life and serve as } \\
\text { foundation to personality. }\end{array}$ & Gosling (2001), p.46 \\
\hline $\begin{array}{l}\text { Temperament: the characteristic style of emotional and behavioural response of an } \\
\text { individual in a variety of different situations that is often, but not invariably, } \\
\text { demonstrated very early in life. It is the stance that an individual takes towards its } \\
\text { environment across time and situations. It refers to styles of responsiveness and not } \\
\text { to specific acts. }\end{array}$ & Box (1999), p. 34 \\
\hline $\begin{array}{l}\text { Temperaments and personalities: integrated behavioural phenotypes and stable traits } \\
\text { that are consistent over time and across situations; broad and consistent dimensions } \\
\text { of individuality. }\end{array}$ & Budaev (1997), p. 399 \\
\hline $\begin{array}{l}\text { Individual animals often behave in a way that distinguishes them from other members } \\
\text { of their species of the same sex and age class. When such differences are consistent } \\
\text { over time, they can be referred to as 'personalities' or 'behavioural style'. }\end{array}$ & Lowe \& Bradshaw (2001) \\
\hline $\begin{array}{l}\text { Coping style: a coherent set of behavioural and physiological stress responses which is } \\
\text { consistent over time and which is characteristic to a certain group of individuals. It } \\
\text { seems that coping styles have been shaped by evolution and form general adaptive } \\
\text { response patterns in reaction to everyday challenges in the natural habitat. }\end{array}$ & Koolhaas et al. (1999) \\
\hline $\begin{array}{l}\text { The expression of individual behavioural and physiological phenotypes or 'coping } \\
\text { styles' is defined as the way individuals cope behaviourally and physiologically with } \\
\text { environmental and social challenges, irrespective of life history state, sex or } \\
\text { motivational state. }\end{array}$ & Pfeffer et al. (2002) \\
\hline
\end{tabular}

a more restrictive meaning than personality, often describing differences in emotionality or describing traits that are demonstrated very early in life (Budaev, 1997; Box, 1999). Given that personality and temperament are frequently distinguished on arbitrary grounds we treat them here as synonyms.

Many definitions in Table 1 refer to both a measurable element (i.e., the expression) and "unobservables", or qualities that are difficult to measure (i.e., the individual dispositions). Similarly, several temperament traits imply inference of psychological mechanisms underlying the expression at the behavioural level. For instance emotionality refers to behavioural and peripheral changes presumed to accompany high sympathetic nervous activity (Archer, 1973), anxiety is the fear of a potential danger (Boissy, 1995; File, 2001), and some definitions of neophobia focus on the fear of novel objects (e.g., Beissinger, Donnay \& Walton, 1994). We think that both these "unobservables" and the inference of psychological properties may restrain ecologists and evolu- tionary biologists from studying temperament; such inherent dispositions are not implied in the definitions of morphology (i.e., the form of living organisms; Oxford Dictionary of English, 2005) or life history (the series of changes undergone by an organism during its lifetime; Oxford Dictionary of English, 2005), two categories of traits commonly studied by ecologists and evolutionary biologists. Based on these considerations, we propose that temperament, personality and individuality describe the phenomenon that individual behavioural differences are consistent over time and/or across situations (Budaev, 1997; Box, 1999; Lowe \& Bradshaw, 2001; Gosling, 2001; Dall et al., 2004). Here "consistent" does not mean that trait values cannot change with age or environmental conditions, but that differences between individuals are largely maintained. Although temperament is considered at the individual level, it can be extended to the other levels, describing for example consistent behavioural differences between families, populations or species. 
We propose, as a working rule, that each temperament trait should be defined according to the ecological situation (sensu Sih et al., 2004a) in which it is measured. The underlying concept is that each term should be operationally defined and its ecological validity tested (see Section V). We divide temperament traits into five categories: (1) shyness-boldness, an individual's reaction to any risky situation, but not new situations. This includes reaction to risky situations, such as predators and humans. Note that 'docility', 'tameness' and 'fearfulness' have been used in the specific context of reaction to humans (Boissy, 1995; Grandin, 1998; Boissy et al., 2005); (2) explorationavoidance, an individual's reaction to a new situation. This includes behaviour towards a new habitat, new food, or novel objects. This situation can also be considered risky if, for example, a new object may represent a potential predator. We have deliberately not included neophobia and neophilia in our terminology because both are considered as part of exploration. Furthermore, from an ecological point of view, we can assume that exploration will be the main target of selection. Neophobia and neophilia are, on the other hand, more relevant to those interested in the mechanisms responsible for individual variation in exploration (see e.g., Greenberg \& Mettke-Hofmann, 2001); (3) activity, the general level of activity of an individual. Activity can interfere with the measurement of exploration or of boldness; it has thus been proposed to obtain a measure of activity in a non-risky and a non-novel environment (Barnett \& Cowan, 1976; Renner, 1990). The last two trait categories are expressed in a social context; (4) aggressiveness, an individual's agonistic reaction towards conspecifics; (5) sociability, an individual's reaction to the presence or absence of conspecifics (excluding aggressive behaviour). Sociable individuals seek the presence of conspecifics, while unsociable individuals avoid conspecifics.

We are conscious of the limits created by the simplification of our terminology; this terminology should be regarded as a working tool, and not an exhaustive list. This simplified terminology is essential to encourage ecological research into temperament. Once we have obtained sufficient information for a large group of species from different ecosystems, we can start generalizing about the ecological and evolutionary role of temperament traits. At that point, we could refine our terminology for temperament traits, using more terms and operational concepts.

This terminology has several advantages:

(1) The five proposed categories do not include the notion of underlying dispositions. Furthermore, we avoid confusion between the terms; here shyness-boldness is used when there is no component of novelty associated with the measured behaviour. When novelty is associated, it is preferable to use exploration-avoidance.

(2) Using a hierarchical model (Fig. 1), temperament traits, like morphological or life-history traits, refer to a category of traits. Each temperament trait can potentially be measured by a set of correlated behavioural or physiological variables. For example, a bird's body size could be measured with wing length, tarsus length, beak size or body mass. Similarly a rodent's exploratory phenotype could be measured by the distance covered and by the frequency of rearing and sniffing in an open-field. Temperament can thus be measured using physiological, hormonal, and/or behavioural indices measured in a specific ecological situation. Choosing a measure depends on a study's goals. Researchers interested in mechanisms would give priority to endocrine, neurobiological and behavioural levels. Alternatively, those more interested in the function of temperament traits would focus on the behavioural level and the consequences of this behavioural variation on fitness. Both approaches are worthwhile and should be integrated for a better understanding of temperament traits.

(3) According to the hierarchical model, we can consider integrated behaviour patterns (sensu Henderson, 1990) as outcomes of the temperament traits categories defined above. This is the case for examples of parental style, dominance, leadership, foraging style, or dispersal. For instance, parental style represents the reactions of a parent towards its progeny when the progeny is in interactions with conspecifics or novel or risky situations; permissive mothers will allow their progeny to interact with conspecifics, whereas restrictive mothers will prevent contact between their progeny and conspecifics (Maestripieri, 1993, 1998; Fairbanks, 1996). In this context, it will be possible to test if one of the five categories of temperament traits affects parental style. These integrated behaviour traits are themselves integrated into a higher level function. For example parental style, fecundity and maternal investment may be considered as important components of lifetime reproductive success. The hierarchical model proposes to put behaviour traits into a network of traits with different levels of interactions and integration. It thus differs from Wilson et al.'s (1994) shyness-boldness model that proposes a more horizontal structure of behaviour traits.

(4) With this terminology we do not presuppose the correlation of all the traits together in a whole "temperament", an idea common to concepts such as personality (Costa \& McCrae, 1992), coping style (Koolhaas, De Boer \& Bohus, 1997; Koolhaas et al., 1999; Pfeffer, Fritz and Kotrschal, 2002) or behavioural syndromes (Clark \& Ehlinger, 1987; Sih et al., $2004 a, b$ ). Traits may also be consistent across functional behavioural categories or contexts (context-generality, the converse of context-specificity; Sih et al., 2004a, b; Coleman \& Wilson, 1998). For example, an individual may be bold in feeding, mating and anti-predator contexts, in which case boldness would appear to be a context-general temperament trait. The extents to which temperament traits correlate with one another and are contextspecific are empirical questions rather than defining features of temperament (Coleman \& Wilson, 1998). Indeed, context-specificity and inter-trait correlation need not be considered as separate questions, since two context-specific traits can be usefully considered as two traits. The evolutionary, functional, proximate, 
and developmental considerations and constraints that determine the degree of context-specificity and intertrait correlation are central to the study of animal temperament.

\section{(3) Properties of temperament traits}

Temperament concepts are frequently associated with responses to novel, risky or challenging situations (Wilson et al., 1994). For example, coping style - a concept close to temperament - corresponds to the responses to social and non-social challenging or novel situations that are consistent between individuals, irrespective of life history state, sex or motivational state (Koolhaas et al., 1997, 1999; Pfeffer et al., 2002). Although temperament does not have to be restricted to novel, risky or challenging situations, it appears to be strongly expressed in these particular conditions, which may explain why researchers have focused on these conditions. Ecologists and evolutionary biologists may also be encouraged to focus on temperament under novel, risky or challenging conditions for this reason, but also because they are determinant for the differential survival and reproduction of individuals.

Temperament traits can often be misleadingly interpreted as bimodal variables, although individuals will often vary along a continuum with two extremes represented as tendencies (shy-bold: Wilson et al., 1994; proactivereactive: Koolhaas et al., 1999). For example, boldness represents the way an individual reacts to a risky situation, with the boldest individuals taking the most risks and shyest ones avoiding risks the most. Here "boldest" and "shyest" are two extreme expressions of boldness rather than two entirely different traits. Various degrees of boldness from very shy to very bold as shown by different individuals are thus considered temperament phenotypes for boldness, whereas boldness is the temperament trait. The bimodal idea of temperament seems to be related to the methodological approach used by some disciplines. For example, the comparison of two strains artificially selected for high and low temperament trait values (see Koolhaas et al., 1999; De Boer, van der Vegt \& Koolhaas, 2003; Drent, van Oers \& van Noordwijk, 2003) will represent the two extreme cases of the continuum present in the original population.

We consider temperament as different from an idiosyncrasy, or a behavioural attribute distinctive to an individual. For example, the fact that a particular cat prefers corn is an idiosyncrasy not a temperament difference. Idiosyncrasies are difficult to study because of their anecdotal nature and we do not consider them further here. Temperament traits should also be distinguished from motivational states (e.g., hunger level; Koolhaas et al., 1999) and from ability traits (e.g., cognitive ability; Winter \& Barenbaum, 1999), though an interaction between these factors will be involved in the expression of a behaviour pattern. For example, an individual of poor competitive ability may be prompted by hunger to be more exploratory, less neophobic, or to take more risks, than it would ordinarily (Reader \& Laland, 2003).

\section{WHY HAVE ECOLOGISTS AND EVOLUTIONARY BIOLOGISTS NEGLEGTED TEMPERAMENT?}

The potential importance of animal temperament to both applied and theoretical studies of ecology and evolution has been widely recognised (e.g., Stamps, 1991; Wilson et al., 1994, Sih et al., 2004a, b), yet relevant empirical studies are generally few and far between (but see Section III.4). Here, we analyse possible reasons for this apparent neglect, evaluate their importance, and note remedies to some of the concerns of ecologists and evolutionary biologists.

\section{(1) Inconsistent terminology, perceived irrelevance and lack of generalization}

Temperament traits have not known the conceptual success of life-history traits (e.g., growth, fecundity, longevity, reproductive success) in evolutionary biology (Roff, 2002). Life-history traits can be measured without ambiguity (e.g., number of eggs to measure fecundity), are comparable among species (longevity in a mouse and an elephant are measured on the same scale), and show a more direct and apparent link with fitness (e.g., the higher the reproductive success the higher the fitness), and thus appear to have strong ecological and evolutionary relevance. A newcomer to temperament studies, however, is frequently faced with a multitude of terms, tests and measures, generally developed with humans in mind (Groothuis \& Carere, 2005). The same trait can be measured by different methods, and the same methods have been used in different fields to measure different traits (Gosling, 2001). For example, boldness can often be associated with the reaction of an animal to a novel object, to a predator, or to a conspecific. Furthermore, experimental protocols are often designed in such a way that it is difficult to understand which behaviour is actually measured. For example, novel environment tests have been criticized because locomotion in forced tests may also reflect behaviour unrelated to exploration (Barnett \& Cowan, 1976; Renner, 1990; Hughes, 1997); namely activity (Russell, 1983), emotionality (Archer, 1973), fearfulness (Boissy, 1995), or neophobia (Greenberg, 1992). Ecologists may be reluctant to use terms such as anxiety, emotionality or fear because they make inferences about underlying psychological mechanisms. This reluctance could be reinforced by the fact that terms and methodology used to study temperament have little clear ecological relevance.

Historically, most personality research has focused on humans and has been conducted by psychologists (Gosling, 2001) or behavioural geneticists (Kagan, Reznick \& Snidman, 1988; Eley \& Plomin, 1997; Plomin \& Caspi, 1999). Despite the success of human personality research, the predominant focus on humans creates some problems (Groothuis \& Carere, 2005). Expanding concepts to include animals risks anthropomorphism, and presently it is not clear to what extent discoveries regarding human temperament relate to animals. For example, terms like 'fear' or 'anxiety' may not correspond to the same psychological state in rodents and humans (Kagan \& Snidman, 2004). Moreover, human 
personality research itself is considered to have a low scientific status, because of its reliance on correlational evidence, the central role played by subjective instruments such as questionnaires, and a historical tendency to describe personality structure rather than examining underlying mechanisms (Pickering \& Gray, 1990). For example, the five-factor model of human personality provides a useful and necessary taxonomy of personality traits, organizing traits along five personality dimensions (Costa \& McCrae, 1992; Digman, 1990; Winter \& Barenbaum, 1999). The neurology or genetics behind personality structure, however, remains poorly understood (Pickering \& Gray, 1990). Although findings such as correlations between human health, mortality, and personality type (Martin, 1998) may act as a useful heuristic for animal studies, it is the causal models of underlying process in humans that will be of maximal value to students of animal temperament. Furthermore, the increasing number of studies showing the central role of the brain serotonin system on temperament in diverse taxa (see below) raises the possibility that findings regarding temperament may be generalizable across species.

Research on non-human animal temperament has typically occurred in the laboratory on domesticated rat and mice strains (Koolhaas et al., 1999), or on the farm with domestic animals (Grandin, 1998; Price, 1999), and the links to reproductive success in natural conditions remain ambiguous. For instance, can observation of a domestic rat in a laboratory open-field test tell us anything significant about its behaviour and ecology in the wild? Many authors consider that this assumption of ecological and evolutionary significance is valid (Boissy, 1995; Koolhaas et al., 1999). Although we agree that laboratory measures may correspond to ecologically relevant traits, we believe that these concerns are best addressed by the empirical study of temperament from an ecological viewpoint.

\section{(2) Reluctance to take an individual-based approach}

Evolutionary biologists have long been interested in individual differences (Darwin, 1859), but often regard individual variation within a population as the raw material on which selection acts rather than an end product of natural selection (Clark \& Ehlinger, 1987; Wilson, 1998; Magurran, 1993; but see Mousseau, Sinervo and Endler, 2000). The optimality approaches of behavioural ecology, for example, often consider individual differences as noise around an adaptive mean (Wilson, 1998; Dall et al., 2004). Such thinking leads to a neglect of whether, how, and why individuals differ in their behaviour (Clark \& Ehlinger, 1987; Magurran, 1993; Wilson, 1998; Sih et al., 2004a). Since many studies use only those individuals that are easily trained, many optimal foraging studies may be based entirely on certain behavioural types, perhaps not representative of the overall characteristics of a natural population. Both the difficulties in marking and following individuals for substantial amounts of time, as well as a fear of pseudoreplication may also lead to a reluctance towards focussing on individual differences. For these reasons, many behavioural studies use one observation per individual observed, an average value over several observations, or use repeated-measure ANOVAs and focus on the betweensubject component. Recent progress in mixed-model methods may increase the use of individual-based approaches (Diaz-Uriarte, 2002; see also Section IV.2).

\section{(3) The lack of a general framework}

Perhaps the lack of interest in temperament traits from ecologists and biologists is only apparent. Indeed the abundant literature on anti-predator behaviour and aggression proves that some temperament traits have a successful history of research. A cursory literature survey illustrates the disequilibrium between the strong impact of some temperament traits taken individually in ecology and the near absence of ecological studies using temperament as a concept. We examined 13 journals from 1989 to 2004 (American Naturalist, Animal Behaviour, Behavioral Ecology and Sociobiology, Behaviour, Behavioural Ecology, Ecology, Ethology, Evolution, Fournal of Animal Ecology, Fournal of Evolutionary Biology, Oikos, Oecologia and the Proceedings of the Royal Society of London Series B). Overall 877 references included the key word "aggression", 58 "aggression" and "fitness", but only seven "aggression" with "personality", "temperament", or "boldness". This suggests that despite the strong interest in aggression, aggressiveness is not explicitly considered to be a temperament trait by ecologists. Recent contributions (Sih et al., 2004a, b), however, provide a strong conceptual basis for the ecological and evolutionary study of sets of correlated behaviours, such as temperament traits, and this, we hope, may inspire research.

\section{(4) Evidence for the ecological importance of temperament}

Despite the situation described above, several pioneering works, briefly reviewed here, demonstrate the utility of integrating temperament within evolutionary ecology research programs.

Thirty years ago, Huntingford (1976a) published a landmark paper documenting differences in aggressiveness, exploratory behaviour, and anti-predator behaviour in three-spined sticklebacks Gasterosteus aculeatus. She exposed the same individuals to a series of behavioural tests, and showed that individuals differed consistently in aggressiveness, that aggressiveness correlated across contexts (individuals that were relatively aggressive towards conspecifics were also relatively aggressive towards heterospecifics), and that individual behaviour was consistent across situations (relatively aggressive individuals were also relatively bold). This was one of the first demonstrations of a behavioural syndrome. Common environment (Giles \& Huntingford, 1984; Huntingford et al., 1994) and quantitative genetics studies showed substantial heritable variation in aggressiveness, and strong genetic correlations between components of the syndrome (Bakker, 1986, 1994). Huntingford's work demonstrated how differences in predator regime between populations could shape temperament (Huntingford et al., 1994). 
Riechert \& Hall (2000) found that individual desert spiders Agelenopsis aperta differed in their anti-predator behaviour and aggressiveness depending on their habitat type. In a resource-limited, highly competitive, arid habitat, spiders are aggressive towards both conspecifics and prey, and bold towards predators. In a food-rich, non-competitive, riparian habitat where predation by birds is high, spiders are shy and non-aggressive. This population difference in behaviour has a genetic basis (Riechert \& Maynard Smith, 1989; Hedrick \& Riechert, 1989), with these traits being genetically related to each other (Riechert \& Hedrick, 1993). Furthermore, transplant experiments showed that the population divergence was favoured by natural selection (Riechert \& Hall, 2000).

During the 1990s, Verbeek, Boon \& Drent (1996) showed that wild great tits Parus major raised under controlled laboratory conditions differed consistently in boldness towards novel objects and exploration of a novel environment, and that these traits and aggressiveness were correlated. Following this discovery, extensive further investigation resulted in one of the most complete examples of the ecological importance of temperament (see Fig. 2B). Artificial selection experiments (Drent et al., 2003; van Oers et al., 2004c; Groothuis \& Carere, 2005; Carere et al., 2003) and field studies (Dingemanse et al., 2002) permitted analysis of the influence of additive genetic, dominance, and environmental effects on individual differences in behaviour, and showed the presence of strong genetic correlations among these traits (van Oers et al., 2004a). In the wild, personality has been shown to affect several traits of ecological importance: dominance (Dingemanse \& de Goede, 2004), natal dispersal (Dingemanse et al., 2003), territory quality and reproductive performance (Both et al., 2005), survival (Dingemanse et al., 2004), offspring recruitment (Dingemanse et al., 2004), and physiological responses to social stress (Carere et al., 2001, 2003). Substantial selection pressures on these traits indicated the importance of temperament traits on the way wild animals cope with fluctuating environmental conditions (Both et al., 2005; Dingemanse et al., 2004).

There has been a long tradition of temperament studies in primatology. For example, S.J. Suomi, J.D. Higley, and their collaborators followed semi-free ranging rhesus macaques Macaca mulatta, providing an impressive portrait of the role of serotonin in the social interactions, life history and ecology of both sexes. Males and females with low cerebrospinal fluid (CSF) levels of 5-hydroxyindoleacetic acid (5-HIAA; a measure of serotonin activity) are impulsive and more likely to take risks (measured as the frequency of capture or of dangerous leaps through the forest canopy: Mehlman et al., 1994; Westergaard et al., 2003b). These males are more aggressive (Mehlman et al., 1995; Higley et al., 1996), less socially affiliative (measured as grooming duration and proximity to group members), emigrate from the natal group earliest, and suffered higher mortalities, as compared to males with high levels of 5-HIAA (Mehlman et al., 1994, 1995; Higley et al., 1996). Low-5-HIAA males are seen less often consorting with oestrus females or involved in heterosexual mounts and insemination (Mehlman et al., 1997). Low-5-HIAA females are more protective of their infants and have a lower reproductive success associated with infant early mortality (Cleveland et al., 2003; Westergaard et al., 2003a). Thus, a suite of variables correlates with 5-HIAA concentration, which is known to be heritable in rhesus macaques (Higley et al., 1996) and appears to correlate with species differences in aggression (Westergaard et al., 1999). The influence of serotonin on aggression has been shown in non-human primates (Mehlman et al., 1995; Higley et al., 1996), and also humans (Coccaro et al., 1997), as well as many other vertebrates (Nelson \& Chiavegatto, 2001; Miczek et al., 2002).

\section{INTEGRATING TEMPERAMENT WITHIN ECOLOGIGAL AND EVOLUTIONARY STUDIES}

We now review potential benefits of an evolutionary ecology approach to the study of temperament. Two of the most important questions regarding temperament in ecology and evolutionary biology are "Do temperament traits play an important ecological or evolutionary role?" and "Why do we observe between-individual variation in behaviour in natural populations"? To answer these questions temperament can be studied at different levels: among individuals within a population (e.g., Réale \& Festa-Bianchet, 2003, Dingemanse et al., 2004; Dingemanse \& Réale, 2005), among populations within a species (e.g., Bell, 2005; Dingemanse \& Réale, 2005), and among species (e.g., Mettke-Hofmann, Winkler \& Leisler, 2002). We argue that temperament should be more often considered in routine ecological programs. Likewise, we offer a series of examples where temperament can provide innovative research objectives to ecologists.

For temperament to add explanatory value to studies of evolutionary ecology, ideally research should follow four steps (Table 2). Firstly, behavioural tests should be developed to provide appropriate and standardized temperament trait measures for the species studied. We expect to detect some variation, repeatability and heritability for the trait measured. Secondly, the tests should be validated by looking at the relationship between the behavioural trait and other trait measures. Relationships with physiological measures would help us understand the mechanisms driving variation at the behavioural level. Relationships with traits of ecological importance would help understanding of the ecological role of temperament traits. Third, linking temperamental variation with fitness differences within a population will allow estimation of the ecological and evolutionary roles of temperament. Finally, intra- and interspecies comparisons will provide ways of testing the ecological and evolutionary role of temperament and constraints on the evolution of temperament traits at a broader scale. We detail each of these steps below.

\section{(1) Measuring temperament traits}

When developing tests to measure temperament traits we expect to find three characteristics (Table 2) in the trait we measure: (a) phenotypic variation; $(b)$ repeatability; and 
A

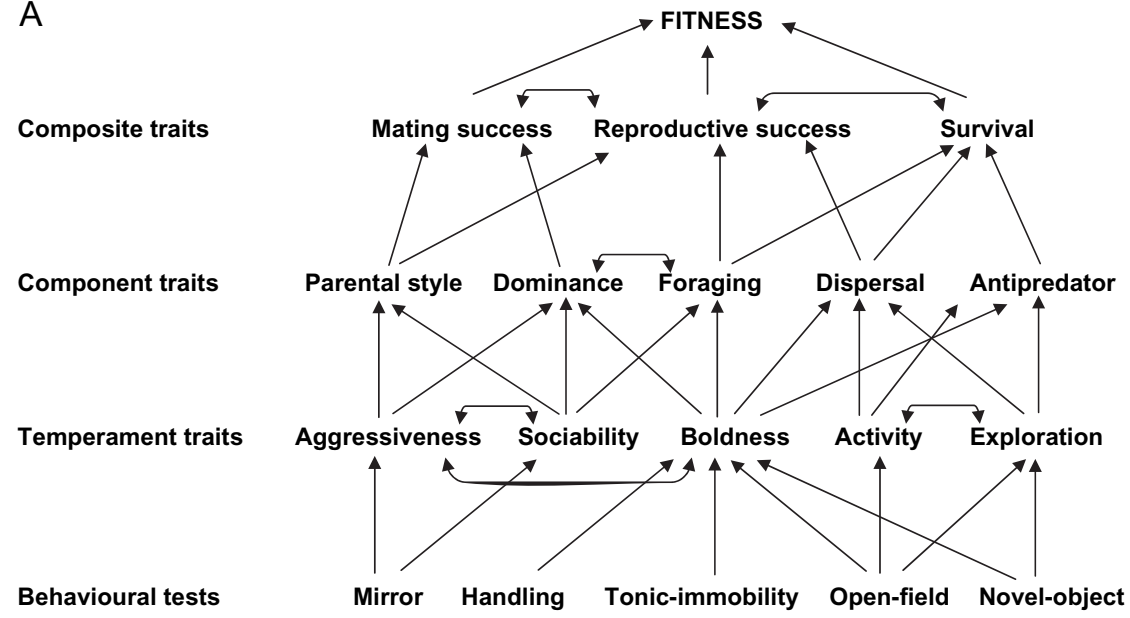

B

Composite traits
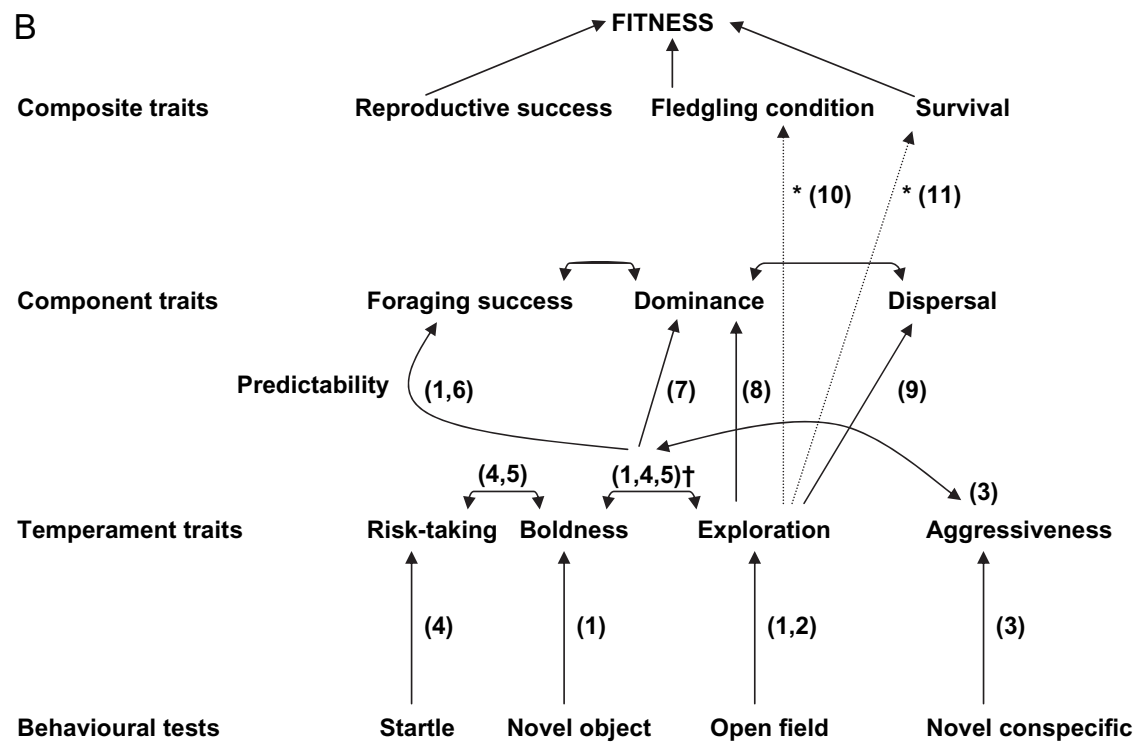

Fig. 2. (A). Flow diagram illustrating the proposed framework for the ecology of temperament traits. Note that the arrows do not represent all possible links between variables. Arrows between tests and temperament traits indicate possible direct measurements. Note that some traits measured with a specific test may be affected by other traits. (B). An example that considers the great tit, Parus major. Single arrows indicate direct relationships between two variables; double arrows indicate correlations between variables. Dotted lines indicate that evidence is lacking for a mediating effect of any of the component traits.

* Fitness consequences of temperament trait variation differ with year and ecological conditions.

$\dagger$ Given the strong correlation between 'boldness' and 'exploration', these traits should be regarded here as the same temperament trait. Note that we report the links made by the authors. Note that trait names used in the figure follow the terminology of the authors of the studies, rather than the terminology developed in the present paper. Numbers in figure: (1) Verbeek et al. (1994); (2) Dingemanse et al. (2002); (3) Verbeek et al. (1996); (4) van Oers et al., (2004b); (5) van Oers et al. (2004a); (6) Marchetti \& Drent (2000); (7) Verbeek et al. (1999); (8) Dingemanse \& de Goede (2004); (9) Dingemanse et al. (2003); (10) Both et al. (2005); (11) Dingemanse et al. (2004).

(c) a genetic basis (i.e., heritability) for the trait variation. Evolutionary ecologists are mainly interested in the mechanisms that drive the evolution of wild species, thus raising the question of the genetic basis and heritability of temperament traits.

\section{(a) Variation}

We would like to encourage the reader to use specific, unambiguous tests designed clearly to address each of the five temperament traits defined in Section II.2. For instance, following the proposed terminology, a test measuring boldness ideally should avoid any component of novelty or should take into account the effects of the change in novelty on the expression of boldness. Our choice of restricting the terminology to the five traits described in Section II.2, is based on the importance of avoiding possible redundancy between the terms commonly used in studies on temperament (i.e., timid $=$ shy; affable $=$ sociable; see the review by Gosling, 2001), which may have been 
Table 2. The four-step program on the ecological role of temperament

\begin{tabular}{|c|c|c|}
\hline Goals & Expected results & Explanations for unexpected results \\
\hline \multirow[t]{2}{*}{$\begin{array}{l}\text { 1. Developing experimental tests } \\
\text { to measure temperament } \\
\text { traits (behaviour) }\end{array}$} & $\begin{array}{l}\text { (a) Variation among individuals } \\
\text { within a population }\end{array}$ & $\begin{array}{l}\text { Strong canalizing selection on the trait, which has } \\
\text { completely eroded the genetic and phenotypic variance } \\
\text { for the trait. All the individuals show exactly the same } \\
\text { reaction. }\end{array}$ \\
\hline & $\begin{array}{l}\text { (b) Repeatability of temperament } \\
\text { trait } \\
\text { (c) Heritability of temperament } \\
\text { trait }\end{array}$ & $\begin{array}{l}\text { Inappropriate test; does not generate individual variation, } \\
\text { because of the presence of Genotype x Environment } \\
\text { interaction combined with the absence of variation for } \\
\text { the trait in the specific ecological situation tested (e.g., the } \\
\text { experimental situation is too overwhelming for the } \\
\text { animals or motivational state differences are not } \\
\text { adequately controlled). }\end{array}$ \\
\hline \multirow[t]{3}{*}{ 2. Validating tests } & $\begin{array}{l}\text { Phenotypic/genetic correlation } \\
\text { between behavioural measures } \\
\text { and other measures } \\
\text { (hormones, neurotransmitters, } \\
\text { physiological variables) }\end{array}$ & $\begin{array}{l}\text { Tools and techniques not precise enough to detect a link } \\
\text { between behavioural and physiological variation. }\end{array}$ \\
\hline & $\begin{array}{l}\text { Experimental validation } \\
\text { (i.e., ecological engineering) }\end{array}$ & Other physiological variables should be used. \\
\hline & $\begin{array}{l}\text { Phenotypic/genetic correlation } \\
\text { with other traits of ecological } \\
\text { importance (e.g., dispersal, } \\
\text { dominance, territory size) }\end{array}$ & $\begin{array}{l}\text { Minor or no ecological or evolutionary role of temperament } \\
\text { traits within the conditions of the study. }\end{array}$ \\
\hline $\begin{array}{l}\text { 3. Linking temperament traits } \\
\text { with fitness }\end{array}$ & $\begin{array}{l}\text { Correlation with fitness indices } \\
\text { (e.g., survival; reproductive } \\
\text { success) }\end{array}$ & $\begin{array}{l}\text { Temporal variability in selection pressures } \\
\text { More fitness-related traits are required by the analyses } \\
\text { Minor or no ecological or evolutionary role of temperament } \\
\text { traits within the conditions of the study. }\end{array}$ \\
\hline $\begin{array}{l}\text { 4. Broad-scale patterns of } \\
\text { variation and covariation in } \\
\text { temperament traits (e.g., } \\
\text { intra- or inter-species } \\
\text { comparisons) }\end{array}$ & $\begin{array}{l}\text { Relationship between particular } \\
\text { ecological conditions and } \\
\text { temperament }\end{array}$ & $\begin{array}{l}\text { Habitat-dependent ontogenetic effects on temperament, } \\
\text { relationship is lost in common-garden experiment } \\
\text { Minor or no ecological or evolutionary role of temperament } \\
\text { traits within the conditions of the study. }\end{array}$ \\
\hline
\end{tabular}

a constraint on the development of ecological research on temperament.

Measurements of temperament traits should be based on experiments that are designed to specifically exclude nontarget behaviours. For instance, fear of novel objects or food should be measured in a familiar environment (e.g., a home cage) to ensure that the measured behaviour does not reflect exploration of the environment but rather behaviour directed to the novel challenge. In order to avoid correlations between behaviours solely caused by the experimental arrangement, standardized methods are required to measure different axes of temperament that may often be correlated (e.g., boldness, exploration, activity). For example, various studies have shown that 'boldness' and 'exploratory behaviour' are correlated (e.g., Huntingford, 1976b; Verbeek, Drent \& Viepkema, 1994) and concluded that temperament is context-general (Kagan et al., 1988; Coleman \& Wilson, 1998). Such correlations between different behaviours, however, may reflect side-effects of the experimental set-up, particularly if all behavioural tests were conducted in a novel environment. For instance, the correlation between predator-inspection behaviour, aggressiveness and exploratory behaviour in three-spined stickleback (Huntingford, 1976b) may not reflect inter-trait correlations but rather individual consistency in fear towards an unfamiliar aquarium (Maier, Vandenhoff \& Crowne, 1988; Budaev, 1997).

We encourage researchers to consider more than one measure of each temperament category (Table 3), just as an organism's body size can be measured using several measures. For example, one could measure boldness by using predator or handler tests following a trappability test, and then test for the redundancy between indices by estimating the strength of the correlation between these two measures. For example, early exploratory behaviour, a combined score for boldness and exploration in great tits (Drent et al., 2003), is genetically highly correlated $(r=0.85)$ with so-called risk-taking behaviour (van Oers et al., 2004a). Van Oers et al. (2004a) interpret this strong genetic correlation as evidence for strong associations between different personality traits, although one could argue that the strong genetic correlation suggests that these different behavioural tests are all measures of the same trait. If it became clear that the two indices are not related, we would have to expand our terminology. Alternatively, when the two indices are strongly related, the use of different tests would validate the measures, and therefore the use of a combined index (e.g., from a principal components 
Table 3. Summary of a terminological and methodological framework for the ecological study of temperament

\begin{tabular}{|c|c|c|c|c|c|}
\hline $\begin{array}{l}\text { Ecological } \\
\text { situation }\end{array}$ & $\begin{array}{l}\text { Temperament traits } \\
\text { and extreme phenotypes }\end{array}$ & Tests $^{1}$ & $\begin{array}{l}\text { Example of } \\
\text { operational definition }\end{array}$ & Example of study & $\begin{array}{l}\text { Examples of ecological } \\
\text { validity (relationship with...) }\end{array}$ \\
\hline \multirow[t]{7}{*}{ Risk-taking } & Boldness & & & & \\
\hline & Bold, docile, tame, unfearful & Predator presentation test & $\begin{array}{l}\text { Avoidance or inspection of } \\
\text { the predator }\end{array}$ & Godin \& Dugatkin (1996) & Risks of predation ${ }^{4,5}$ \\
\hline & Shy, untamed, fearful & Predator stimulus test & $\begin{array}{l}\text { Startle response near a food } \\
\text { patch and latency to return } \\
\text { to the food source }\end{array}$ & Van Oers et al. $(2004 b)$ & Survival $^{4}$ \\
\hline & & Response to threat stimuli & $\begin{array}{l}\text { Latency to enter a trap or } \\
\text { probability of capture }\end{array}$ & Coleman \& Wilson (1998) & Mating success in males ${ }^{4}$ \\
\hline & & Trappability $^{6}$ & $\begin{array}{l}\text { Tendency to fight, attack, } \\
\text { or bite }\end{array}$ & $\begin{array}{l}\text { Malmkvist and } \\
\text { Hansen (2001) }\end{array}$ & Social status ${ }^{4}$ \\
\hline & & $\begin{array}{l}\text { Resistance to handlers / } \\
\text { Trapezov stick test }\end{array}$ & Latency to move & Jones (1982) & Reproductive success ${ }^{4}$ \\
\hline & & Tonic immobility test ${ }^{7}$ & & Erhard et al. (1999) & \\
\hline Novelty $^{2}$ & Exploration $^{3}$ & & & & \\
\hline Habitat & Exploratory, neophilic & Open-field test ${ }^{8}$ & $\begin{array}{l}\text { Distance covered / defecation } \\
\text { and urination / time } \\
\text { spent rearing }\end{array}$ & $\begin{array}{l}\text { Hall (1934); Archer } \\
\quad(1973)\end{array}$ & Dispersal $^{4}$ \\
\hline Object & Unexploratory, neophobic & Novel environment test & $\begin{array}{l}\text { Same as open field / per cent } \\
\text { of time spent with the head } \\
\text { in the holes }\end{array}$ & File \& Wardill (1975) & Reproductive success ${ }^{4}$ \\
\hline Food & & $\begin{array}{l}\text { Hole-board test } \\
\text { Novel object test }\end{array}$ & $\begin{array}{l}\text { Latency to approach a } \\
\text { novel object close to a food } \\
\text { source. Per cent of time spent } \\
\text { in contact with the object }\end{array}$ & Greenberg (1984) & $\begin{array}{l}\text { Risks of predation }{ }^{4,5} \\
\text { Survival }^{4} \\
\text { Dietary and habitat } \\
\text { characteristics }^{5} \\
\text { Behavioural flexibility }^{5}\end{array}$ \\
\hline \multirow[t]{2}{*}{ General activity } & Activity & & & & \\
\hline & $\begin{array}{l}\text { Active } \\
\text { Inactive }\end{array}$ & $\begin{array}{l}\text { Open-field test / } \\
\text { cage activity test }\end{array}$ & Distance covered & Wilson et al. (1976) & $\begin{array}{l}\text { Dispersal }^{4} \\
\text { Risks of predation } \\
4,5\end{array}$ \\
\hline \multirow[t]{4}{*}{ Social } & Sociability & & & & \\
\hline & Social, sociable & Separation test & $\begin{array}{l}\text { Reaction to separation from the } \\
\text { group / latency to join the } \\
\text { group when isolated }\end{array}$ & Faure \& Mills (1998) & Reproductive success ${ }^{4}$ \\
\hline & $\begin{array}{l}\text { Asocial } \\
\text { Agoressiveness }\end{array}$ & & & & Parasitic load $^{4}$ \\
\hline & Aggressive & Mirror image stimulus ${ }^{9}$ & Aggressive display or contact & Armitage (1986) & $\begin{array}{l}\text { Competitive abilities (food, } \\
\text { space, territory, mate) }\end{array}$ \\
\hline
\end{tabular}


analysis) would be preferred (for example Drent et al., 2003). Another issue is absence of variation in response to a test (Table 2). For example, in a novel-object experiment Eastern chipmunks (Tamias striatus) showed no reaction to a small ball (D. Réale, unpublished results). They continued their foraging routine, and foraged without exploring the ball or even pushed the ball away in order to collect the seeds underneath. When tested with a pair of wool socks, however, chipmunks showed longer and variable latencies to approach the food in the presence of the object. Both objects were "new" to the chipmunks, although given its shape and structure, the pair of socks may have carried information representing "predatory" cues for the chipmunks that a spherical, smooth ball does not. Some tests may also create a situation that is too overwhelming for all the individuals tested, thereby not showing any variation among them. This kind of situation may not be exceptional, but may be rarely reported by scientists, who tend to select tests that generate variation. Absence of variation could also be caused by the presence of genotype $\mathrm{x}$ environment $(\mathrm{GxE})$ interaction with no variation at the specific ecological situation of the test (Table 2). This would imply that past selection pressures have eroded the genetic and phenotypic variance of the trait within the range of ecological conditions tested. Running the test in different ecological situations may be a way to reveal any $\mathrm{GxE}$ for the trait (see below).

\section{(b) Repeatability ( $r$ )}

Repeatability can be used as a first estimate of individual consistency in a trait (Boake, 1989; Falconer \& Mackay, 1996). Repeatability illustrates how strong the individual consistency for the trait is in the population and is the proportion of phenotypic variation explained by the variation among individuals (Falconer \& Mackay, 1996). It can be obtained by running an analysis of variance with individuals included as a fixed factor, when a minimum of two measures of the trait for each individual have been taken (Falconer \& Mackay, 1996). It can also be obtained from a mixed model where individual is a random effect (Diaz-Uriarte, 2002). Repeatability is a unit-free standardized measure that can readily be compared among samples (e.g., populations, species). Low repeatability for a temperament trait could be observed if, for example, the conditions chosen for the experimental test do not generate behavioural variation (i.e., all individuals react in the same way to the experimental set-up; Table 2) or by high withinindividual variation relative to among-individual variation. When we estimate repeatability we assume that the environment in which the replicated measures have been taken is constant. Though seemingly similar to the experimenter, however, successive replications of a test for the same individual may differ due to micro-environmental effects, thereby changing the expression of the behaviour (Henderson, 1990). Furthermore, learning and habituation may affect the novelty aspect of an open-field test replicated several times (Greenberg \& Mettke-Hofmann, 2001; Wahlsten, 2001). For example, great tits were quicker to explore a novel environment when confronted with it 
a second time and this effect is stronger when the animal is tested shortly after its initial test (Dingemanse et al., 2002). In the same way, the latency of an individual to enter a trap may decrease with repeated exposure because the trap loses its novel dimension. Habituation may be circumvented by exposing subjects to different types of novel objects (e.g., Verbeek et al., 1994), although repeated exposures to different novel objects may also lead to habituation, if the animal can habituate to novelty itself, as opposed to particular novel properties. The test will thus no longer represent the same challenge to the subject. Disentangling the effects of novel and non-novel components of an object/ habitat on the reaction of an individual implies that studies on temperament should not restrict measures to one condition, but should also integrate environmental variation and temporal dimensions (e.g., with learning; Seferta et al., 2001). A reaction norm approach could be helpful to circumvent such difficulties: it represents the phenotypic variation of genotypes (here as individuals) across an environmental gradient (here as novelty; Fig. 3). By running a mixed-model analysis using several replicated measures of a trait for each individual it is possible to estimate individual variation for that trait (individual is used as a random effect), and the general effect of the environment (for example the rank of the trial is used as a fixed effect). In addition, an interaction between trial and individual would indicate that individuals differ in the way they respond to the experimental arrangement with experience (Fig. 3). The absence of a significant interaction would indicate that all the individuals habituate at the same rate. This absence of interaction, combined with significant individual variation for the temperament trait, also indicates a potential behavioural syndrome where individual experience is the environmental situation (Sih et al., 2004b). The reaction norm approach can be generalized to any other gradient (e.g., importance of the risk; number of competitors; age of the individual; seasonal variation).

\section{(c) Heritability}

Repeatability is assumed to set an upper limit to heritability (Boake, 1989). High repeatability and individual consistency can also come from several other non-genetic sources: maternal effects; common environmental effects and individual histories; experience; learning; and the environmental conditions specific to each individual (Falconer \& Mackay, 1996). Repeatability provides initial evidence that among-individual variation is caused by factors intrinsic to the individual, but does not allow for separation of the genetic and non-genetic components of the variance in a temperament trait. Heritability $\left(h^{2}\right)$ is a standardised index of the proportion of phenotypic variance explained by additive genetic variance of the trait, and represents its evolutionary potential (i.e., the ability of a trait to change its mean and distribution across generations, as a result of selection; Falconer \& Mackay, 1996; Roff, 1997; Lynch \& Walsh, 1998). Because temperament corresponds to individual behavioural differences that are consistent over time and across situations, heritability should occupy a central position in the study of temperament. Most studies to date have been conducted under laboratory conditions and in many cases were explicitly aimed at excluding rather than studying environmental sources of variation. Other sources of variation of temperament traits, particularly ontogenetic changes or those induced by the environment (Markowitz et al., 1998; Lowe \& Bradshaw, 2001; Maestripieri, Tomaszycki \& Carroll, 1999) have largely been neglected. Examples of non-genetic sources of between-individual variation are maternal influences on offspring temperament mediated via variable transmission of androgens in the yolk of bird eggs (Schwabl, 1993) or in the effects of intrauterine testosterone on the behaviour and life histories of female rodents (Compaan et al., 1992; Clark \& Galef, 1995). Examples of within-individual sources of variation in temperament include seasonality in birds (Dingemanse et al., 2002), ontogenetic changes in behaviour of birds
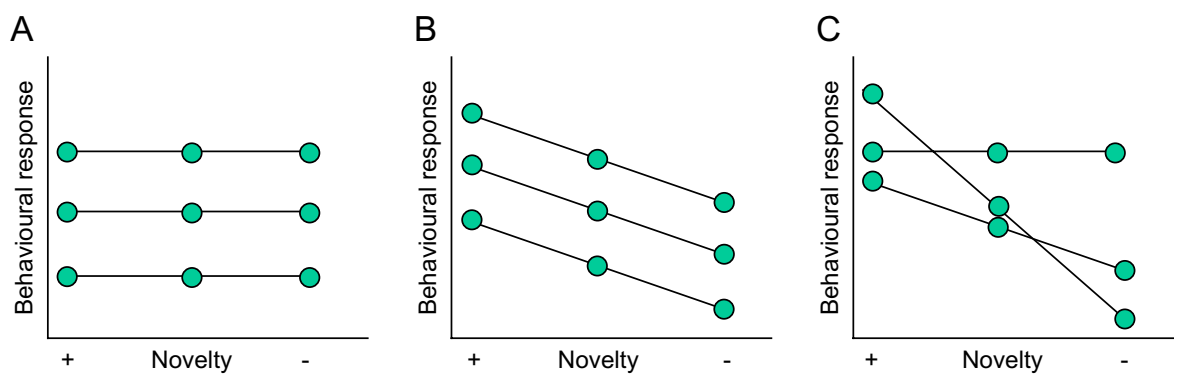

Fig. 3. A reaction norm approach to the study of temperament that aims to disentangle exploration from boldness, when experience or habituation can affect the individual response to a test. Each line represents the behavioural response of a given genotype, or individuals experiencing the experimental arrangement three consecutive times (three points). With this approach we assume that the animals experience a decline in novelty. In A, genotypes vary in their response to the experimental arrangement, but do not perceive the change in novelty (i.e., the reaction norm is flat and phenotypic plasticity is null); in this case exploration and boldness are identical. In $\mathrm{B}$, behavioural responses decline with time, indicating phenotypic plasticity, but all the genotypes react in the same way (i.e., null $\mathrm{GxE}$ interaction). In this case exploration and boldness are different overall; they can be considered as genetically identical (genetic correlation between exploration and boldness equals 1). In C, genotypes differ in how fast they change their response to the experimental arrangement with experience (i.e., GxE occurs). In this case, exploration and boldness are two different traits. 
(Carere et al., 2003), laboratory rodents (Koolhaas et al., 1999) and wild marmots (Armitage \& Van Vuren, 2003), and learning in fish (Huntingford et al., 1994). If not considered, all these effects may bias the estimate of heritability. For example, individual variation in the rate of habituation will generate uncontrolled GxE interaction, compromising estimation of temperament trait heritability.

Classical breeding experiments and analyses of variance (ANOVAs) (see Falconer \& Mackay, 1996; Roff, 1997; Lynch \& Walsh, 1998), or artificial selection experiments (Trut, 1999; Drent et al., 2003), provide a way of measuring the genetic basis of a trait in the laboratory. A recent statistical method, the "animal model", is particularly promising for studies of temperament traits in natural populations (Réale, Festa-Bianchet \& Jorgenson, 1999; Kruuk, 2004; see Bell, 2005, for application to temperament) as it is appropriate for complex pedigrees (Lynch \& Walsh, 1998). Methods that permit us to estimate which part of the phenotypic variance in a temperament trait is caused by additive genetic, maternal variance, common environmental or permanent environmental effects would provide valuable information on the mechanisms at the origin of temperament differences within a population. For instance, a strong permanent environmental variance of a temperament trait would indicate that a large portion of the individual variation for that trait was generated during the early life of the individual, but has neither a genetic basis, nor is the result of maternal influence. In the same way, a strong common environmental effect would illustrate the possibility that the environment in which an individual is reared influenced its temperament. When the data collected on a temperament trait involve replicated tests, seasonal variation, ontogenetic effects, or environmental differences, a mixed model with genotype as a random effect and with trial, season, age, or environment as a fixed effect will allow for accurate assessments of heritability, phenotypic plasticity, and GxE of that trait. Mixed-model ANOVAs with full-sib or a half-sib design (Fry, 1992), or with recent advances in random regression using the animal model (Schaeffer, 2004) could be used for estimating these parameters.

\section{(2) Validating measures of temperaments traits}

\section{(a) Biological and ecological validity}

For logistical and methodological reasons, temperament traits should be measured in an experimental context as we can rarely measure them by direct observation. Furthermore, the need for large sample sizes for estimation of heritabilities or selection pressures, means tests should be rapid and easy to perform. Direct observation of individuals and their ranking according to a predetermined scale has, however, been used by psychologists (Gosling, 2001) but can be criticised because of the subjectivity of the interpretation of observations. The experimental approach is open to criticism since it places an animal in a situation that is irrelevant to its natural conditions. Nevertheless, in the experimental approach, we are more interested in differences between individuals in a broader context, than the behaviour in the experimental context per se. For instance, we assume that the behaviour of the mouse in an open field reveals its reactions to a new and open environment and thus its exploratory tendencies.

When possible, testing the biological and ecological validity of the test by looking at the relationship between the temperament trait and physiological traits (i.e., biological validation) or ecologically important traits (i.e., ecological validation) is recommended. Biological validation allows determination of the mechanisms responsible for the variation in temperament. There is extensive evidence that behavioural variation in temperament may reflect underlying hormonal and neuro-endocrine variation among individuals (Bohus et al., 1987; Boissy, 1995; Koolhaas et al., 1999; Kagan \& Snidman, 2004; Groothuis \& Carere, 2005).

Ecological validation is important to temperament research, because it provides a way to integrate temperament traits in the ecological framework, and put temperament at the interface between ecological factors and selection. Results supporting this link will encourage ecologists to consider temperament in their studies. The link between a behavioural measure of temperament and an ecologically important trait can be studied by using phenotypic correlations between the two traits. For example, dispersal distance in the wild was related to experimental tests of exploratory behaviour in great tits (Dingemanse et al., 2003) and killifish Rivulus hartii (Fraser et al., 2001). It is also possible to compare an individual's behaviour measured in an experimental test (e.g., aggressive reaction to a mirror image) with observations in the same context in a more natural situation (e.g., rate of aggressive interactions). Such validation may yield intriguing insights as shown by a study on great tits where the correlation between dominance in the wild and experimental tests of exploratory behaviour (which predicts dominance in the laboratory: Verbeek et al., 1994, 1999) was positive for territorial adults but negative for non-territorial juveniles (Dingemanse \& de Goede, 2004). Experimental validation is also possible by manipulating the phenotype (e.g., through hormonal implants) of some individuals and by comparing their behaviour with a control group (i.e., phenotypic engineering: Ketterson \& Nolan, 1999; see below). Alternatively, ecological validation can be obtained by estimating the genetic correlation between the measured traits and the ecologically important trait. An array of methods is available to estimate genetic correlations between temperament traits [breeding designs: Lynch \& Walsh (1998); artificial selection: van Oers et al. (2004a); pedigree analyses and the animal model: Kruuk (2004)].

\section{(b) Behavioural syndromes}

The concept of genetic correlation is central to defining a trait and whether two measurements can be considered as one unique trait or as two different traits. The genetic correlation between two characters or between measures of a character in two different environmental conditions gives a standardised index of the degree to which the covariance of the two characters is governed by a common set of genes, generally caused by pleiotropy or linkage disequilibrium 
(Via \& Lande, 1985; Roff, 1997; Lynch \& Walsh, 1998). From a mechanistic point of view, a strong positive genetic correlation would indicate common genetic and physiological pathways between the two traits (Crusio, 2001; Sih et al., 2004a, b). Alternatively if the correlation is negative, it would reflect the competition for resources allocated to each trait (Roff, 1997). From an evolutionary point of view, a strong genetic correlation illustrates past co-evolution between the traits (Roff, 1997; Lynch \& Walsh, 1998), and will prevent independent evolution of both traits (Roff, 1997; Lynch and Walsh, 1998; Sih et al., 2004a, b). An evolutionary and ecological approach to the study of temperament will thus include estimates of phenotypic and genetic correlations between the traits (Sih et al., 2004b).

Genetic and phenotypic correlations are appropriate for testing for the presence of a behavioural syndrome. On the other hand, a behavioural syndrome can still occur even in the presence of GxE effects. For example, a weak GxE interaction corresponds to a strong genetic correlation across the two environments, and a genetic correlation of 1 can still be found with GxE effects if genetic variances differ in the two environments. Evidence of genetic correlation between temperament traits and other life-history or morphological traits (Table 4) indicates the ecological and evolutionary importance of temperament traits.

The extent to which temperament traits are independent or form part of a behavioural syndrome is a controversial and important issue (Wilson et al., 1994; Koolhaas et al., 1997, 1999; Sih et al., 2004a, b). It is critical to the understanding of the phenotypic organisation, genetic structure and evolutionary history of temperament traits and to determining the generality of findings across contexts, populations, and species. On one hand, implicit in the concepts of behavioural syndromes and coping styles (Koolhaas et al., 1997, 1999; Sih et al., 2004b; Groothuis \& Carere, 2005) is the existence of a set of related behavioural and physiological traits. On the other hand, this integrated view of temperament has been challenged by the hypothesis that divergent and context-specific selection pressures could favour the evolution of context-specific temperament traits, with weak phenotypic or genetic correlations across contexts (Wilson et al., 1994; Wilson, 1998). Both hypotheses have been supported by empirical studies on various models (presence of a behavioural syndrome: Riechert \& Hedrick, 1993; Benus \& Rondigs, 1996; Groothuis \& Carere, 2005; Sih et al., 2004a; absence of a behavioural syndrome: Spoolder et al., 1996; Coleman \& Wilson, 1998; Réale et al., 2000; D'Eath \& Burn, 2002; Bell, 2005).

The nature of the outcome may depend on several possible explanations. In support of the behavioural syndrome hypothesis, a common neuroendocrine system is known to mediate a whole suite of behaviour patterns (Boissy, 1995; Bucan \& Abel, 2002). Furthermore, alternative coping strategies result from individual differences in reactivity of the sympathetic nervous system (high in active copers) and the hypothalamic-pituitary-adrenal axis (high in passive copers) in response to stress (Koolhaas et al., 1997, 1999), indicating that fundamental differences in neuroendocrinological and behavioural organisation underlie variation in animal personality (Bohus et al., 1987; Boissy, 1995;
Groothuis \& Carere, 2005). This gene-neurophysiologybehaviour pathway should be illustrated by strong phenotypic and genetic correlations between the temperament traits studied whether these are different traits or a given trait measured in different contexts (Table 4; see also Sih et al., 2004a, b). The reason why behavioural traits and temperament are mediated by a common neuroendocrine system is not well understood. We can advance three reasons: (1) the evolution of a large number of neurophysiological systems would be costly, thereby creating a strong constraint on the diversity of possible behavioural responses and thus a strong integration between temperament traits. Overall, a few neurophysiological systems appear to play an equivalent role in many different invertebrate or vertebrate organisms (e.g., serotonergic and dopaminergic systems; Koolhaas et al., 1999; Gosling 2001; Libersat \& Pflueger, 2004); (2) the homeostasis of the organism necessitates feedbacks and controls at the neurophysiological level, and this can only be done with a limited set of neurophysiological systems. The evolution of gene-neurophysiology-behaviour pathways would thus be limited to a small number of well-integrated systems; (3) traits involved in a given function co-evolve, and are thus characterised by strong genetic correlations between them, suggesting the existence of functional, developmental, and evolutionary modularity of organisms (Cheverud, 1996; Wagner, 1996; see also the literature on cognitive modularity: Reader, 2006).

Explanations for the absence of behavioural syndromes are multiple. Such empirical negative findings may result from methodological limits to these studies; the fact that the relationship between the two traits has been cancelled out by their common relationship with another variable (Shipley, 2000), or from a lack of statistical power. As Wilson pointed out (Wilson et al., 1994; Wilson, 1998), selection could lead to the independent evolution of temperament traits according to the context in which they are measured. Genetic correlation is assumed to constrain the independent evolution of the two traits, and a behavioural syndrome should in principle be constant within and across populations (Sih et al., 2004b; Bell, 2005). Positive correlations between temperament traits, however, can be observed within a population but not across populations because of long-term differences in the selection regime of two populations on a combination of temperament traits (Bell, 2005), founder effects that create linkage disequilibrium at the origin of the correlation (Whitlock, Phillips \& Fowler, 2002), gene flow, or genetic drift (Armbruster \& Schwaegerle, 1996).

\section{(3) Linking temperament with fitness}

We raised above the importance of past selection pressures on the organisation of temperament traits. Few attempts have been made to study temperament and its functional consequences in natural populations (Wilson et al., 1994), meaning that the importance of temperament for fitness remains largely unknown (Clark \& Ehlinger, 1987; Wilson, 1998; Dingemanse \& Réale, 2005). Here we discuss methods to study the fitness consequences of temperament 


\begin{tabular}{|c|c|c|c|c|c|c|}
\hline Temperament trait ${ }^{1}$ & Other traits & Relation & Approach & Species & Common name & Reference \\
\hline & \multicolumn{6}{|l|}{ Reproduction } \\
\hline Anti-predator & Mating song & - & $\mathrm{PC}$ & Gryllus integer & Field cricket & Hedrick (2000) \\
\hline Boldness & Mating success ${ }^{2}$ & + & PG & Poecilia reticulata & Guppy & Godin \& Dugatkin (1996) \\
\hline Boldness & Age at sexual maturity & - & $\mathrm{PC}$ & Ovis canadensis & Bighorn sheep & Réale et al. (2000) \\
\hline Boldness & Lifetime reproductive success & + & $\mathrm{PC}$ & Ovis canadensis & Bighorn sheep & Réale et al. (2000) \\
\hline Boldness & Hatching success & - & $\mathrm{PC}$ & Euprymna tasmanica & Dumpling squid & Sinn et al. (2006) \\
\hline Docility & Age at sexual maturity & - & $\mathrm{PC}$ & Ovis canadensis & Bighorn sheep & Réale et al. (2000) \\
\hline Tameness & Age at sexual maturity & - & AS & Mustela vison & Mink & Klotchkov et al., (1998) \\
\hline Tameness & Fecundity & + & AS & Mustela vison & Mink & Klotchkov et al., (1998) \\
\hline Tameness & Onset of oestrus & + & AS & Mustela vison & Mink & Malmkvist et al. (1997) \\
\hline Tameness & Length of gestation & - & AS & Mustela vison & Mink & Malmkvist et al. (1997) \\
\hline Fearfulness & Reproductive status & - & PC & Acinonyx jubatus & Cheetah & Wielebnowski \& Brown (1998) \\
\hline Aggression & Maternal effort & - & AS & Mus musculus & Mouse & Benus \& Rondigs (1996) \\
\hline Aggression & Paternal behaviour & - & $\mathrm{PC}$ & Cichlasoma nigrofasciatum & Convict cichlid & Budaev et al. (1999) \\
\hline Aggressiveness $^{3}$ & Breeding success & - & $\mathrm{PC}$ & Diceros bicornis & Black rhinoceros & Carlstead et al. (1999) \\
\hline Exploration & Parental behaviour & + & $\mathrm{PC}$ & Cichlasoma nigrofasciatum & Convict cichlid & Budaev et al. (1999) \\
\hline Exploration $^{4}$ & Litter size & + & AS & Mus musculus & House mouse & Rauw et al. $(2000)$ \\
\hline Exploration & Fertility & - & AS & Orictolagus cuniculus & Rabbits & Daniewski \& Jezierski (2003) \\
\hline Exploration & Nest success & - & $\mathrm{PC}$ & Parus major & Great tit & Both et al. (2005) \\
\hline Exploration & Offspring size & - & $\mathrm{PC}$ & Parus major & Great tit & Both et al. (2005) \\
\hline Exploration & Fledging mass & $-/+$ & $\mathrm{PC}$ & Parus major & Great tit & Both et al. (2005) \\
\hline Exploration & Number of recruits & $-/+$ & $\mathrm{PC}$ & Parus major & Great tit & Dingemanse et al. (2004) \\
\hline Neophobia & Mothering ability & - & AS & Ovis aries & Domestic sheep & Kilgour \& Szantar-Coddington (1995) \\
\hline \multirow[t]{2}{*}{ Activity ${ }^{4}$} & Litter size & + & AS & Mus musculus & House mouse & Rauw et al. (2000) \\
\hline & \multicolumn{6}{|l|}{ Growth } \\
\hline Docility & Weight gain & + & $\mathrm{BD}$ & Bos taurus & Domestic cattle & Gauly et al. (2001) \\
\hline Tameness & Weight gain & + & $\mathrm{PC}$ & Bos taurus & Domestic cattle & Fell et al. (1999) \\
\hline Tameness & Weight gain & + & $\mathrm{PC}$ & Bos taurus/indicus & Domestic cattle & Voisinet et al. (1997) \\
\hline Exploration & Weight gain & + & $\mathrm{PC}$ & Rivulus hartii & Trinidad killifish & Fraser et al. (2001) \\
\hline Aggressiveness & Weight gain & $-/+$ & $\mathrm{PC}$ & Salmo trutta & Brown trout & Höjesjö et al. (2004) \\
\hline Aggressiveness & Weight gain & + & $\mathrm{PC}$ & Salmo trutta & Brown trout & Höjesjö et al. (2002) \\
\hline Boldness & Weight gain & + & $\mathrm{PC}$ & Gasterosteus aculeatus & Threespined stickleback & Ward et al. (2004) \\
\hline Boldness & Weight gain & + & $\mathrm{PC}$ & Perca fluviatilis & Eurasian perch & Westerberg et al. (2004) \\
\hline Fearfulness & Body mass & - & AS & Coturnix japonica & Japanese quail & Jones et al., (1991) \\
\hline Exploration & Weaning mass & - & AS & Orictolagus cuniculus & Rabbit & Daniewski \& Jezierski (2003) \\
\hline Neophobia/exploration ${ }^{4}$ & Body mass & - & AS & Coturnix japonica & Japanese quail & Jones et al. (1991) \\
\hline \multirow[t]{2}{*}{ Boldness } & Body size & - & $\mathrm{PC}$ & Brachyraphis episcopi & Poeciliid fish & Brown \& Braithwaite (2004) \\
\hline & \multicolumn{6}{|l|}{ Behaviour } \\
\hline Fearfulness & Tameness & - & AS & Coturnix japonica & Japanese quail & Mills \& Faure (2000) \\
\hline Sociability & Tameness & + & AS & Coturnix japonica & Japanese quail & Mills \& Faure (2000) \\
\hline Social impulsivity & Dominance & Quad + & $\mathrm{PC}$ & Cercopithecus aethiops & Vervet monkey & Fairbanks (2001) \\
\hline Social impulsivity ${ }^{5}$ & Aggression & $\widetilde{0.78}$ & $\mathrm{BD}$ & Cercopithecus aethiops & Vervet monkey & Fairbanks et al. (2004) \\
\hline
\end{tabular}




\begin{tabular}{|c|c|c|c|c|c|c|}
\hline Exploration & Dispersal & + & $\mathrm{PC}$ & Parus major & Great tit & Dingemanse et al. (2003) \\
\hline Exploration & Dispersal & $-1+$ & PC & Mus musculus & House mouse & Krackow (2003) \\
\hline Exploration & Dominance & $-1+$ & $\mathrm{PC}$ & Parus major & Great tit & Dingemanse \& de Goede (2004) \\
\hline Exploration & Dominance & + & $\mathrm{PC}$ & Parus major & Great tit & Verbeek et al. (1996) \\
\hline Boldness & Dominance & + & $\mathrm{PC}$ & Salmo trutta & Brown trout & Sundström et al. (2004) \\
\hline Neophobia (habitat) & Dispersal & + & $\mathrm{PC}$ & Rivulus hartii & Trinidad killifish & Fraser et al. (2001) \\
\hline Aggressivness $^{6}$ & Coping & + & LC & Mus musculus & House mouse & Benus (2001) \\
\hline Fighting ability & Various traits ${ }^{7}$ & + & $\mathrm{LC}$ & Bos taurus & Domestic cow & Plusquellec et al. (2001) \\
\hline Risk-taking & Various traits ${ }^{8}$ & + & AS & Parus major & Great tit & van Oers et al. $(2004 a)$ \\
\hline $\begin{array}{l}\text { Tameness } \\
\text { Personality }\end{array}$ & $\begin{array}{l}\text { Health } \\
\text { Immunity } \\
\text { Simian Immunodeficiency } \\
\text { Virus responses }\end{array}$ & + & $\mathrm{PC}$ & $\begin{array}{l}\text { Bos taurus } \\
\text { Macaca mulatta }\end{array}$ & $\begin{array}{l}\text { Domestic cattle } \\
\text { Rhesus macaque }\end{array}$ & $\begin{array}{l}\text { Fell et al. (1999) } \\
\text { Capitanio et al. (1999) }\end{array}$ \\
\hline Boldness & $\begin{array}{l}\text { Survival } \\
\text { Survival }\end{array}$ & + & PSA & Ovis canadensis & Bighorn sheep & Réale \& Festa-Bianchet (2003) \\
\hline Docility & Survival & + & PSA & Ovis canadensis & Bighorn sheep & Réale \& Festa-Bianchet (2003) \\
\hline Neophobia & Survival & - & $\mathrm{PC}$ & Rattus norvegicus & Norway rat & Cavigelli \& McClintock (2003) \\
\hline Exploration & Survival & $+/-$ & PSA & Parus major & Great tit & Dingemanse et al. (2004) \\
\hline
\end{tabular}

1 Trait names follow the terminology of the authors of the studies.

2 Mating success is measured as female preference.

3 We chose the term aggressiveness instead of chasing/stereotypy/mouthing, which, according to the authors, are traits indicative of arousal or agitation to social stimuli.

4 Varies according to year and sex.

${ }^{5}$ Heritability estimates for two components of social impulsivity, the approach index which is the tendency of an individual to stay within $1 \mathrm{~m}$ of an intruder, and the aggression index which is the rate threats and agonistic displays directed towards an intruder.

6 Across-sex genetic correlation (aggression was selected in males and coping tested on females).

7 Aggressiveness, neophobia, sociability, and tameness in two breeds selected and not selected for fighting ability.

8 Early exploratory, boldness and exploration as adult in two lines selected for high and low risk taking.

9 Four personality traits: sociability, confidence, equability and excitability. 
and adaptive explanations for the maintenance of genetic variation within populations.

\section{(a) Measuring selection}

Natural selection can be directly measured by the covariance between traits and fitness, allowing estimation of both the strength (Lande, 1979; Lande \& Arnold, 1983) and shape (i.e., directional, disruptive, stabilizing, correlational) of selection (Brodie, Moore \& Janzen, 1995). Such estimation models can be used to assess the way selection acts on correlated characters (Lande \& Arnold, 1983; Kingsolver et al., 2001), and so are particularly suitable for the study of selection on temperament traits (Réale et al., 2000). To date, only two field studies have used such an approach in wild populations, measuring both heritability (see Réale et al., 2000; Dingemanse et al., 2002, 2004; Dingemanse \& Réale, 2005) and components of fitness under different environmental conditions (Réale \& FestaBianchet, 2003; Dingemanse et al., 2004, Both et al., 2005). In bighorn ewes Ovis canadensis, weaning success increased with boldness (Réale et al., 2000). Furthermore, boldness was related to survival during years of high predation but not during years of low predation by cougars Puma concolor (Réale \& Festa-Bianchet, 2003). In great tits Parus major, slow-exploring females had the lowest probability of nest failure and assortative pairs of extreme phenotype (i.e., either slow-slow or fast-fast pairs) produced heaviest offspring in all of four years (Both et al., 2005). Whilst the direction of selection on temperament during the breeding phase did not differ between years (Both et al., 2005), outside the breeding season it fluctuated between years, sexes, and components of fitness (Dingemanse et al., 2004). Selection in this case was coincidental with the occurrence of masting by beeches Fagus sylvaticus, a factor that affects competitive regimes of these birds (Perdeck, Visser \& Balen, 2000). In both studies, selection pressures varied according to environmental conditions, although definitive identification of the important environmental changes would require sufficient replication to show statistically the link between selection and environment. These examples emphasize the importance of long-term longitudinal studies to measure selection: individuals encounter many different social and physical environments during their lives. These studies also illustrate that single components of fitness may not accurately predict an individual's overall fitness, as the direction of selection may differ between various components of fitness (e.g., survival versus reproductive output).

Manipulation of the environment or phenotypic engineering could facilitate the study of selection. This could be done by measuring the survival and reproductive success of individuals whose phenotype has been manipulated; such as using agonists or antagonists of some neurotransmitters involved in temperament variation (e.g., tryptophan and fluoxetine increase and cyproheptadine and fenfluramine decrease 5-hydroxytryptamine (5-HT) activity, respectively, affecting dominance acquisition in male vervet monkeys Cercopithecus aethiops; Raleigh et al., 1991). The path analysis method proposed by Scheiner, Mitchell \& Callahan (2000), a method derived from phenotypic selection analysis, has great potential to estimate selection pressures on a set of hierarchically organised temperament traits.

The phenotypic selection approach may offer another way to investigate whether or not selection can act on a whole suite of traits, and lead to the co-evolution of temperament traits. In bighorn ewes Ovis canadensis, selection seems to disfavour the combination of low levels of boldness and of docility, although the fitness consequences of the interaction between the two traits have not been tested (Réale et al., 2000; Réale \& Festa-Bianchet, 2003). Furthermore, in three-spine stickleback Gasterosteus aculeatus the phenotypic correlation between aggressiveness and boldness differed between populations (Bell 2005) and is higher for populations exposed to predators (N.J. Dingemanse, J. Wright, A. Kazem, D. Thomas, R. Hickling \& N. Dawnay, in preparation), suggesting correlational selection on those traits. Hence, future fitness studies should attempt to address under which conditions natural selection favours the evolution of correlated suites of behaviours. Focusing on the fitness consequences of a single temperament trait without considering interaction among traits may give misleading results.

Selection studies on temperament traits could provide several insights. For example, we still do not know what components of fitness (survival at different stages, mating success, fecundity, reproductive success) are affected by temperament traits, or how and in what conditions temperament phenotypes are advantageous or disadvantageous. Studies in the future may help us understand if selection favours plasticity or canalisation of temperament traits. Can we observe antagonistic selection according to sex, and what are the consequences of such a selection pattern on the maintenance of variance in temperament traits? More information on the role of temperament as a factor in sexual selection is needed.

\section{(b) Adaptive explanations for the maintenance of variance in temperament traits}

The relative importance of the different processes for the persistence of within-population variance in temperament traits (i.e., selection-mutation balance, spatiotemporal or frequency-dependent selection, selection-migration balance) is largely unknown (Wilson, 1998). Theoretical modelling suggests that fluctuating selection pressures can help to maintain quantitative genetic variation at higher levels than expected from mutation alone (Burger \& Gimelfarb, 2002). Game theory and the evolutionarily stable strategy approach provide a framework to assess the costs and benefits of alternative behaviours (Magurran, 1993; Dall et al., 2004). In the case of temperament traits, both frequency- and density-dependent processes are likely to contribute to the maintenance of high levels of variation (Wilson et al., 1994; Dall et al., 2004), because the social environment is probably an important determinant of the relation between temperament and fitness. For instance, bird studies have shown that individuals differ in social aggression and foraging behaviour (Verbeek et al., 1996; Marchetti \& Drent, 2000), with the pay-offs of alternative strategies frequency dependent (Barnard \& Sibly, 1981; 
Koops \& Giraldeau, 1996). Such frequency-dependent games could also involve cooperation instead of competition, as shown in white-throated sparrows, Zonotricia albicollis, a species where a chromosomal inversion caused a polymorphism (resulting in 'tan-striped' types that are less aggressive than 'white-striped' types). Ninety-eight per cent of birds pair disassortatively (Houtman \& Falls, 1994), partly because certain pair combinations make better teams during chick-feeding (Knapton \& Falls, 1983). The role of social organisation in the maintenance of individual variation could be addressed indirectly by comparing phenotypic variation in behaviour among social and solitary species. Models also predict that temporal variation in selection can maintain a mix of phenotypically flexible and inflexible genotypes (Wilson \& Yoshimura, 1994). Many species live in temporally fluctuating environments, and it is an open question as to why some individuals and species are relatively inflexible in their behaviour instead of showing higher plasticity (Wilson et al., 1994). An important question is to what extent variation in temperament and behavioural syndromes, and limits and costs associated with phenotypic plasticity constrain or reflect selection on behavioural flexibility (Wilson et al., 1994; Koolhaas et al., 1997, 1999; Dingemanse et al., 2004). Importantly, note that the adaptive explanations for the maintenance of variation in temperament traits given above only explain the co-existence of different temperament types given that individuals show consistent behaviour. That is, none of the afore-mentioned explanations explain why individuals are consistent over time, contexts, or situations. There is thus a strong need for a theoretical framework that explains at the same time why different temperament types coexist and why individuals have temperament types (Dall et al., 2004).

Comparative studies of the amount of genetic variation between trait categories provide an alternative way to investigate the effect of past selection pressures on temperament traits relative to other trait categories. Strong and persistent directional selection on a trait should erode the additive genetic variance, relative to the dominance variance, and thus decrease the trait's heritability (Mousseau \& Roff, 1989; Crnokrak \& Roff, 1995; Merilä \& Sheldon, 1999; Stirling, Réale \& Roff, 2002). Comparing the average value of standardized indices of variation such as heritability, coefficient of additive genetic and residual variance (Houle, 1992; Merilä \& Sheldon, 1999; Stirling et al., 2002), or dominance variance (Crnokrak \& Roff, 1995) for temperament traits relative to other types of traits could therefore provide valuable information about the selection regime of temperament traits. Temperament traits generally show significant heritability, averaging 0.31 (Table 5), a value similar to those observed for behaviour or life-history traits (Stirling et al., 2002). Variance is not only affected by selection, however, but also seems to depend on $\mathrm{GxE}$ interaction or epistasic effects (Merilä \& Sheldon, 1999; Stirling et al., 2002). More estimates of standardized indices of variation for more temperament traits are needed before we can provide any detailed study of the relationship between temperament and fitness. Studies on great tits Parus major provide an example of how the combination of fitness and quantitative genetics studies can provide clues towards the history of selection on temperament traits in natural populations. Studies in the wild showing fluctuating selection on temperament traits (Dingemanse et al., 2004), and back-cross experiments based on selection lines indicating high levels of both additive and dominance variance (Drent et al., 2003; van Oers et al., 2004c) both suggest the absence of strong consistent directional selection on this type of trait (Mousseau \& Roff, 1989; Roff, 1997).

\section{(4) Temperament traits as adaptation: comparative studies}

To investigate temperament traits as adaptations, it is insufficient to show that the trait affects current fitness. The selective forces that have resulted in past evolutionary changes are not necessarily the same forces acting on contemporary populations (e.g., Bennett \& Owens, 2002), so to elucidate fully the ultimate explanations for links between temperament and ecology, we also need to know how present-day patterns result from historical events (Losos \& Miles, 1994). This can be done using comparative approaches, based on the comparison of populations or species that differ in a given temperament trait or set of traits. Such an approach may also be useful in determining general principles regarding the potential evolutionary and ecological role of temperament that apply across taxa, as well as allowing tests of hypotheses otherwise difficult to examine (Losos \& Miles, 1994).

\section{(a) Intra-species population comparison}

A classical approach to the study of adaptation in the wild is the comparison of populations living in different environments, and the correlation between population phenotypes and environmental characteristics (Mousseau et al., 2000; Reznick \& Travis, 2003). This method has provided interesting results on temperament and behavioural adaptation in the wild (Arnold \& Bennett, 1984; Magurran, 1993; Huntingford et al., 1994; Clarke \& Boinski, 1995). For example, fish populations living in sites with high risks of predation show higher boldness, predator inspection scores, and faster escape response than those living in safer sites (Huntingford, 1982; Magurran, 1993; Huntingford et al., 1994; O'Steen, Cullum \& Bennett, 2002). Similarly differences in habitat have been shown to shape variation in boldness and aggressiveness in desert spiders, Agelenopsis aperta (Riechert \& Hall, 2000). Island populations of birds generally show lower neophobia and higher exploration than mainland bird populations (Greenberg \& MettkeHofmann, 2001). Population comparison has a limit: different environmental conditions experienced by the populations may counteract genetic effects on interpopulation differences in phenotypic expression (Conover \& Schultz, 1995). One way of disentangling environmental from genetic effects is to raise individuals from different populations in similar environmental conditions where all the observed variation among populations is expected to be 
Table 5. Evidence for genetic effects on the variation in temperament traits in animals. Studies are separated into three categories: (1) repeatability, (2) heritability, and (3) genetic difference between populations. Method: $\mathrm{R}=$ repeatability; BD = heritability/ breeding design; AS = artificial selection; $\mathrm{POP}=$ population comparisons (common-garden experiment); IL $=$ strain or inbred-line comparison. "+" sign indicates for the presence of significant within-individual consistency, among-line or among-population variation without providing estimates

\begin{tabular}{|c|c|c|c|c|c|}
\hline Temperament trait ${ }^{1}$ & Relation & Species & Name & Method & Reference \\
\hline \multicolumn{6}{|l|}{ Repeatability $^{2}$} \\
\hline Boldness & + & Lepomis gibbosus & Pumpkinseed sunfish & $\mathrm{R}$ & Coleman \& Wilson (1998) \\
\hline Boldness & 0.36 & Ovis canadensis & Bighorn sheep & $\mathrm{R}$ & Réale et al. (2000) \\
\hline Docility & 0.86 & Ovis canadensis & Bighorn sheep & $\mathrm{R}$ & Réale et al. $(2000)$ \\
\hline Fearfulness ${ }^{3}$ & 0.34 & Diceros bicornis & Black rhinoceros & $\mathrm{R}$ & Carlstead et al. (1999) \\
\hline Tameness & $0.29-0.41$ & Diceros bicornis & Black rhinoceros & $\mathrm{R}$ & Carlstead et al. (1999) \\
\hline Social impulsivity & 0.83 & Cercopithecus aethiops & Vervet monkey & $\mathrm{R}$ & Fairbanks (2001) \\
\hline Exploratory ${ }^{4}$ & $0.27-0.66$ & Parus major & Great tit & $\mathrm{R}$ & Dingemanse et al. (2002) \\
\hline Neophobia (food) & + & Lepomis gibbosus & Pumpinkseed sunfish & $\mathrm{R}$ & Coleman \& Wilson (1998) \\
\hline \multicolumn{6}{|l|}{ Heritability $\left(h^{2}\right)$} \\
\hline Anti-predator & 0.45 & Thamnophis radix & Garter snake & $\mathrm{BD}$ & Arnold \& Bennett (1984) \\
\hline Risk-taking & 0.19 & Parus major & Great tit & AS & van Oers et al. $(2004 b)$ \\
\hline Boldness & 0.53 & Parus major & Great tit & AS & Drent et al. (2003) \\
\hline Boldness ${ }^{5}$ & $0.04 / 0.002$ & Gasterosteus aculeatus & Three-spine stickleback & $\mathrm{BD}$ & Bell (2005) \\
\hline Boldness $^{6}$ & $0.21 / 0.08$ & Euprymna tasmanica & Dumpling squid & $\mathrm{BD}$ & Sinn et al. (2006) \\
\hline Docility & 0.28 & Bos taurus & Domestic cows & $\mathrm{BD}$ & Le Neindre et al. (1996) \\
\hline Docility $^{7}$ & $0.18-0.61$ & Bos taurus & Domestic cows & $\mathrm{BD}$ & Gauly et al. (2001) \\
\hline Confidence/human ${ }^{8}$ & $0.12-0.20$ & Alopex lagopus & Blue fox & AS & Kenttämies et al. (2002) \\
\hline Fearfulness/human & 0.38 & Mustela vison & Domestic mink & AS & Hansen \& Møller (2001) \\
\hline Fearfulness/human & $0.17-0.42$ & Bos taurus & Domestic cattlr & $\mathrm{BD}$ & Morris et al. (1994) \\
\hline Fearfulness & 0.32 & Gallus gallus & Domestic chicken & AS & Campo \& Carnicer (1993) \\
\hline Fearfulness & 0.56 & Coturnix coturnix & Japanese quail & $\mathrm{BD}$ & Gerken \& Petersen (1992) \\
\hline Reactivity ${ }^{6}$ & $0.89 / 0.0$ & Euprymna tasmanica & Dumpling squid & $\mathrm{BD}$ & Sinn et al. (2006) \\
\hline Social impulsivity ${ }^{9}$ & 0.25 & Cercopithecus aethiops & Vervet monkey & $\mathrm{BD}$ & Fairbanks et al. (2004) \\
\hline Aggression $^{9}$ & 0.61 & Cercopithecus aethiops & Vervet monkey & $\mathrm{BD}$ & Fairbanks et al. (2004) \\
\hline Aggression $^{5}$ & $0.01 / 0.14$ & Gasterosteus aculeatus & Three-spine stickleback & $\mathrm{BD}$ & Bell (2005) \\
\hline Maternal protectiveness & 0.09 & Bos taurus & Domestic cattle & $\mathrm{BD}$ & Morris et al. (1994) \\
\hline Exploratory ${ }^{4}$ & $0.22-0.61$ & Parus major & Great tit & $\mathrm{BD}$ & Dingemanse et al. (2002) \\
\hline Exploratory & $0.15-0.31$ & Orictolagus cuniculus & Rabbit & AS & Daniewski \& Jezierski (2003) \\
\hline Activity $^{5}$ & $0.05 / 0.016$ & Gasterosteus aculeatus & Three-spine stickleback & $\mathrm{BD}$ & Bell (2005) \\
\hline Activity $^{6}$ & $0.67 / 0.05$ & Euprymna tasmanica & Dumpling squid & $\mathrm{BD}$ & Sinn et al. (2006) \\
\hline \multicolumn{6}{|l|}{ Genetic differences } \\
\hline Anti-predator & + & Phoxinus phoxinus & Minnow & POP & Magurran (1993) \\
\hline Anti-predator & + & Gasterosteus aculeatus & Three-spine stickleback & POP & Huntingford et al. (1994) \\
\hline Anti-predator & + & Agelenopsis aperta & Spider & POP & Riechert \& Hedrick (1993) \\
\hline Anti-predator & + & Gasterosteus aculeatus & Three-spine stickleback & POP & Bell \& Stamps (2004) \\
\hline Exploratory & + & Mus musculus & Inbred mouse & IL & Dellu et al. $(2000)$ \\
\hline Various traits ${ }^{10}$ & + & Mus musculus & Inbred mouse & IL & Holmes et al. (2002) \\
\hline Various traits ${ }^{11}$ & + & Oncorhyncus masou & Cherry salmon & IL & Iguchi et al. (2001) \\
\hline
\end{tabular}

1 Trait names used in the table follow the terminology of the authors of the studies.

2 When several estimates of repeatability and heritability were provided we report only heritability.

3 Correlations between scores for two traits ("allows touching" and "approaches when called") given by keepers during two surveys separated by two years.

4 Range for two populations and two sexes.

5 Estimates in two different populations.

${ }_{7}^{6}$ Estimates of $h^{2}$ in a threat and in a feeding context, respectively.

7 Range of estimates for docility scores before and during handling at two different ages, in German Angus and Simmental cows.

8 Estimates from two populations in Norway and Finland.

9 Fairbanks et al. (2004) provide $h^{2}$ estimates for two components of social impulsivity, the approach index which is the tendency of an individual to stay within $1 \mathrm{~m}$ of an intruder, and the aggression index which is the rate of threats and agonistic displays directed towards an intruder.

10 Exploratory activity and anxiety-like behaviour.

11 Five principal components analysis factors related to anti-predator, activity, anxiety, greediness, carefulness. 
genetic in origin (the common-garden approach; Mousseau et al., 2000). The common-garden approach can also be extended to study evolutionary constraints or trade-offs; one could do so by looking at the correlation between two phenotypic traits measured in different populations (Roff, Crnokrak \& Fairbairn, 2003). An alternative is reciprocal transplants of individuals between the two populations (Conover \& Schultz, 1995). Reciprocal transplants offer the possibility to look at the interaction between genes and the environment on a trait's phenotypic expression (Carroll et al., 2001), and allow a measurement of selection by comparing the fitness of indigenous and transplanted individuals (Riechert \& Hall, 2000).

\section{(b) Interspecific comparative studies}

The most common use of the comparative approach is to test whether a trait is adapted for a particular function (Martins \& Hansen, 1997). The association between a temperament trait and other traits or ecological conditions can be studied from the information provided by the measure of those traits for a set of species (Webster \& Lefebvre, 2001; Marples, Roper \& Harper, 2003). Using this approach, Greenberg (2003) tested the "Neophobia Threshold Hypothesis" the idea that specialist species are more neophobic than ecologically plastic species, because neophobia reduces the probability of investigating and incorporating a new resource in the repertoire of a species. In support of this hypothesis, the specialized chestnut-sided warbler Dendroica pensylvanica is more neophobic than the more plastic bay-breasted warbler Dendroica castanea (Greenberg, 2003). This hypothesis was confirmed with wild-caught individuals from two other species, although work on naïve captive-reared birds provided contrary results (Greenberg, 2003).

Comparison of more than two species increases the power of such approaches. Comparative methods, however, have rarely been used to study temperament (but see Mettke-Hofmann et al., 2002; Richardson, 2001). In a pioneering study in zoo animals, Glickman \& Sroges (1966) placed a diverse set of novel objects in the cage of over 200 species of mammals and reptiles, and used this information to describe patterns of object exploration within and between species. Extending this approach, Mettke-Hofmann et al. (2002) examined the link between ecological factors and neophobia and exploration in 61 parrot species in captivity. Neophobia was higher for insectivorous than for folivorous birds, potentially reflecting the relatively high costs of approaching novel food items for insectivorous species compared to folivorous ones. Exploration was uncorrelated with neophobia, and was higher in species that live on forest edges or on islands, and that eat nuts, suggesting that exploration is primarily influenced by the value of information. Exploration was also more intense in migratory than in resident species (Mettke-Hofmann et al., 2004).

The interest of the comparative approach goes beyond the test of the adaptive hypotheses: one could examine the functional relationships and trade-offs between two traits, the existence of constraints (e.g., the importance of phylogenetic inertia in the variation of a trait), and the ecological and evolutionary implication of temperament (e.g., the role of temperament in the evolutionary diversification in a taxon).

The comparative approach can therefore be successfully applied to a variety of questions on temperament, although it is not exempt from difficulties. A major stumbling block is the quantification of temperament traits in species with different lifestyles: how should results from novel object tests conducted on the house mouse, the three-toed sloth or the Asian elephant be compared? Although one can in principle apply the same method to quantify a temperament trait for a set of species, whether the measure is actually comparable across species is not so straightforward. Novel object experiments should take account of the variability of habitat preference among species; a standardized novel test on the ground, for example, may lead to differences between terrestrial and arboreal species, as the latter species will be more reluctant to approach and explore novel objects on the ground. One solution to this problem is to compare temperament in closely related species, based on their physiological, morphological and ecological similarities. However, this decreases the generality of the results, and potentially removes biologically meaningful variation in the studied trait. Alternatively, one could use a multiple regression approach that includes potentially confounding effects as covariates (e.g., body size or basal metabolic rate). Another option would be to use physiological surrogates of temperament traits (e.g., monoamine levels), provided that among-species variation in these traits is higher than withinspecies variation. Although these measures are indirect, they are likely to be less subject to observational error and context-dependent biases (Kamil, 1994).

Species may resemble one another in their temperament, not because of independent, convergent evolution in response to specific ecological conditions, but instead because of common ancestry. Modern techniques use phylogenetic information to deal with this problem of non-independence (Felsenstein, 1985; Harvey \& Pagel, 1991; Garland et al., 1993; Garland, Bennet \& Rezende, 2005). Another potential danger of the phylogenetic-based methods is that, like any correlational approach, the association between two variables may be caused by their common link with a third variable (Bennett \& Owens, 2002). Consequently, a proper comparative analysis of temperament traits should previously have identified and controlled for potential confounding factors that could inflate or obscure the studied relationship. Furthermore, it is essential to estimate the within-species consistency in the trait (i.e., the trait has to be species-specific) by running mixed models in which species are coded as a random factor. The problem of establishing a causal link between the variables under study may in part be overcome with methods that allow estimation of ancestral states (Harvey \& Pagel, 1991). Alternatively, Hansen's adaptation method may be used to estimate the impact of a specified environment on the evolution of a given trait (Hansen, 1997) and path analysis may help establish the most likely causal scenarios $(\mathrm{Li}, 1975)$. These techniques can potentially be applied to study the causal link between a temperament trait and another trait or an ecological factor (e.g., neophobia and dietary generalism). 


\section{GONGLUSIONS}

(1) Our aim was to build a general framework for the ecological and evolutionary study of temperament and to review the evidence that temperament traits are heritable, linked to fitness, and correlate with several other important traits. We hope this framework and compilation of evidence, combined with the growing general interest in the evolutionary ecology of temperament and the diversity of empirical approaches available, stimulates new progress. We predict that temperament will form an important part of future research on various ecological topics.

(2) Temperament appears to affect the various ways an individual interacts with its environment, whether in its reactions with predators, food sources, and habitat, or in its social or sexual interactions with conspecifics.

(3) Temperament phenotypes will be favoured or disfavoured by selection depending on the particular ecological conditions experienced by the population. Furthermore, individual differences in temperament may affect variation in habitat use or assortative mating, and thus will create conditions for non-random mating.

(4) Temperament may have important consequences for several ecological topics, such as: $(a)$ population dynamics and genetics (i.e., dispersal, individual movement, gene flow, and the genetic composition of meta-populations); $(b)$ landscape ecology (i.e., changes in the structure of the landscape will affect the movement of individuals differently according to their temperament); $(c)$ community ecology (i.e., individual variation in some sets of correlated temperament and morphological traits may be viewed as functional sub-categories in the organisation of communities); (d) invasion biology (i.e., could temperament be an important factor in the invasiveness syndrome?); and $(e)$ speciation (i.e., temperament variation may be responsible for the geographic and reproductive isolation of individuals characterised by particular combinations of behavioural and morphological and life-history traits).

\section{ACKNOWLEDGMENTS}

We are grateful to Don L. Kramer for his contributions at every stage of the study and to Alison Bell, Christiaan Both, Adi Boon, Claudio Carere, Sasha Dall, Piet Drent, Luc-Alain Giraldeau, Julien Martin, Amandine Pierre, Andy Sih, Kees van Oers, and Jonathan Wright for helpful discussion. This research was supported by grants from the Natural Sciences and Engineering Council of Canada (D.R., S.M.R.), a Ramón y Cajal grant (D.S.), and a TALENT-fellowship grant of the Netherlands Organisation for Scientific Research (N.J.D.).

\section{REFERENGES}

Allport, G. W. (1937). Personality: A Psychological Interpretation. Henry Holt, New York.
Archer, J. (1973). Tests for emotionality in rats and mice: a review. Animal Behaviour 21, 205-235.

Armbruster, W. S. \& Schwaegerle, K. E. (1996). Causes of covariation of phenotypic traits among populations. Fournal of Evolutionary Biology 9, 261-276.

Armttage, K. B. (1986). Individuality, social behavior, and reproductive success in yellow-bellied marmots. Ecology 67, 1186-1193.

Armitage, K. B. \& Van Vuren, D. H. (2003). Individual differences and reproductive success in yellow-bellied marmots. Ethology Ecology and Evolution 15, 207-233.

Arnold, S. J. \& Bennett, A. F. (1984). Behavioural variation in natural populations. III: antipredator displays in the garter snake Thamnophis radix. Animal Behaviour 32, 1108-1118.

BAKker, T. C. M. (1986). Aggressiveness in sticklebacks (Gasterosteus aculeatus L.): a behavioural-genetic study. Behaviour, 98, 1-143.

BAKker, T. C. M. (1994). Genetic correlations and the control of behavior, exemplified by aggressiveness in sticklebacks. Advances in the Study of Behavior, 23, 135-171.

Barnard, C. J. \& Sibly, R. M. (1981). Producers and scroungers: a general model and its application to captive flocks of House Sparrows. Animal Behaviour 29, 543-550.

Barnett, S. A. \& Cowan, P. E. (1976). Activity, exploration, curiosity and fear: an ethological study. Interdisciplinary Science Review 1, 43-62.

Beissinger, S. R., Donnay, T. J., Walton, R. (1994). Experimental analysis of diet specialization in the snail kite. The role of behavioural conservatism. Oecologia 100, 54-65.

Bell, A. M. (2005). Behavioural differences between individuals and two populations of stickleback (Gasterosteus aculeatus). Fournal of Evolutionary Biology 18, 464-473.

Bell, A. M. \& Stamps, J. A. (2004). Development of behavioural differences between individuals and populations of sticklebacks, Gasterosteus aculeatus. Animal Behaviour 68, 1339-1348.

Bennett, P. M. \& Owens, I. P. F. (2002). Evolutionary Ecology of Birds: Life Histories, Mating Systems and Extinction. Oxford University Press, Oxford.

Benus, R. F. (2001). Coping in female mice bidirectionally selected for male aggression. Behaviour 138, 997-1008.

Benus, R. F. \& Rondigs, M. (1996). Patterns of maternal effort in mouse lines bidirectionally selected for aggression. Animal Behaviour 51, 67-75.

Boske, C. R. B. (1989). Repeatability: its role in evolutionary studies of mating behavior. Evolutionary Ecology 3, 173-182.

Bohus, B., Benus, R. F., Fokkema, D. S., Nyakas, C. A., Van Oortmerssen G. A., Prins, A. J. A., De Ruiter A. J. H., Scheurink, A. J. W. \& Steffens, A. B. (1987). Neuroendocrine states and behavioural and physiological stress responses. In Progress in Brain Research, volume 72 (eds. E. R. de Kloet, V. M. Wiegant and D. de Wied), pp. 57-70. Elsevier.

Borssy, A. (1995). Fear and fearfulness in animals. Quaterly Review of Biology 70, 165-191.

Boissy, A. \& Bouissou M. F. (1995). Assessment of individual differences in behavioural reactions of heifers exposed to various fear-eliciting situations. Applied Animal Behaviour Science 46, 17-31.

Boissy, A., Fisher, A. D., Bouix, J. Hinch. G. N. \& Le Neindre, P. (2005). Genetics of fear in ruminant livestock. Livestock Production Science 93, 23-32.

Both, C., Dingemanse, N. J., Drent, P. J. \& Tinbergen, J. M. (2005). Pairs of extreme personalities have highest reproductive success. Fournal of Animal Ecology 74, 667-674. 
Box, H. O. (1999). Temperament and socially mediated learning among primates. In Mammalian Social Learning: Comparative and Ecological Perspectives (eds. H. O Box and K. R. Gibson), pp. 3356. Cambridge University Press, Cambridge.

Boyce, W. T. \& Ellis, B. J. (2005). Biological sensitivity to context: I. an evolutionary-developmental theory of the origins and functions of stress reactivity. Development and Psychopathology. 17, 271-301.

Brodie, E. D., Moore, A. J. \& Janzen, F. J. (1995). Visualizing and quantifying natural selection. Trends in Ecology and Evolution 10, 313-318.

Brown, C. \& Braithwaite, V. A. (2004). Size matters: a test of boldness in eight populations of the poeciliid Brachyraphis episcopi. Animal Behaviour 68, 1325-1329.

Bucan, M. \& Abel, T. (2002). The mouse: genetics meets behaviour. Nature Review Genetics 3, 114-123.

Budaev, S. V. (1997). "Personality" in the guppy (Poecilia reticulata): A correlational study of exploratory behavior and social tendency. Fournal of Comparative Psychology 111, 399-411.

Budaev, S. V., Zworykin, D. D. \& Mochek, A. D. (1999). Individual differences in parental care and behaviour profile in the convict cichlid: a correlation study. Animal Behaviour 58, 195-202.

Burger, R. \& Gimelfarb, A. (2002). Fluctuating environments and the role of mutation in maintaining quantitative genetic variation. Genetical Research 80, 31-46.

Buss, A. H., Ghess, S., Goldsmith, H. H., Hinde, R. A., Mccall, R. B., Plomin, R Rothbart, M. K., \& Thomas, A. (1987). What is temperament: Four approaches. Child Development 58, 505529.

Campo, J. L. \& Carnicer, C. (1993). Realized heritability of tonic immobility in white leghorn hens: A replicated single generation test. Poultry Science 72, 2193-2199.

Capitanio, J. P., Mendoza, S. P. \& Baroncelli, S. (1999). The relationship of personality dimensions in adult male rhesus macaques to progression of simian immunodeficiency virus disease. Brain Behaviour Immunology 13, 138-154.

Carere, G., Groothuis, T. G. G., Mostl, E., Daan, S. \& KoolmaAs, J. M. (2003). Fecal corticosteroids in a territorial bird selected for different personalities: daily rhythm and the response to social stress. Hormones and Behavior 43, 540-548.

Carere, C., Welink, D., Drent, P. J., Koolhaas, J. M. \& Groothuis, T. G. G. (2001). Effect of social defeat in a territorial bird (Parus major) selected for different coping styles. Physiology \&ా Behavior 73, 427-433.

Carlstead, K., Mellen, J. \& Kleiman, D. G. (1999). Black rhinoceros (Diceros bicornis) in US zoos: I. Individual behavior profiles and their relationship to breeding success. Zoo Biology 18, 17-34.

Garroll, S. P., Dingle, H., Famula, T. R. \& Fox, G. W. (2001). Genetic architecture of adaptive differentiation in evolving host races of the soapberry bug, Fadera haematoloma. Genetica 112-113, $257-272$.

Caspi, A., Harrington, H., Moffitt, T. E., Begg, D., Dickson, N., Langley, J. \& Silva, P. A. (1997). Personality differences predict health-risk behaviours in young adulthood: evidence from a longitudinal study. Fournal of Personality and Social Psychology 73, 1052-1063.

Cavigelli, S. A. \& Mcclintock, M. K. (2003). Fear of novelty in infant rats predicts adult corticosterone dynamics and an early death. Proceedings of the National Academy of Science, USA 100, 16131-16136.
Cheverud, J. M. (1996). Developmental integration and the evolution of pleiotropy. American Zoologist 36, 44-50.

Clark, A. B. \& Ehlinger, T. J. (1987). Pattern and adaptation in individual behavioral differences. Perspectives in Ethology 7, $1-47$.

Clark, L. A. \& Wilson, D. (1999). Temperament: A new paradigm for trait psychology. In Handbook of Personality: Theory and Research, 2nd edn. (Eds. L. A. Pervin and O. P. John), pp. 399423. The Guilford Press, New York.

Clark, M. M. \& Galef, B. G. (1995). Prenatal influence on reproductive life-history strategies. Trends in Ecology and Evolution 10, 151-153.

Clarke, A. S. \& Boinski, S. (1995). Temperament in nonhuman primates. American Fournal of Primatology 37, 103-125.

Cleveland, A., Westergand, G. C., Trenkle, M. K. \& Higley, J. D. (2003). Physiological predictors of reproductive outcome and mother-infant behaviors in captive rhesus macaque females (Macaca mulatta). Neuropsychopharmacology 29, 109-910.

Coccaro, E. F., Kavoussi, R. J., Trestman, R. L., Gabriel, S. M., Copper, T. B. \& Siever, L. J. (1997). Serotonin function in human subjects: intercorrelations among central 5-HT indices and aggressiveness. Psychiatry Research 73, 1-14.

Coleman, K. \& Wilson, D. S. (1998). Shyness and boldness in pumpkinseed sunfish. Individual differences are context-specific. Animal Behaviour 56, 927-936.

Companan, J. G., Deruiter, A. J. H., Koolhaas, J. M., Van Oortmerssen, G. A., \& Bohus, B. (1992). Differential-effects of neonatal testosterone treatment on aggression in 2 selection lines of mice. Physiology and Behaviour 51, 7-10.

Conover, D. O. \& Schultz, E. T. (1995). Phenotypic similarity and the evolutionary significance of countergradient variation. Trends in Ecology and Evolution 10, 248-252.

Costa, P. T., Jr. \& Mccrae, R. R. (1992). Four ways five factors are basic. Personality and Individual Differences 13, 653-665.

Crnokrak, P. \& Roff, D. A. (1995). Dominance variance: association with selection and fitness. Heredity 75, 530-540.

Crusio, W. E. (2001). Genetic dissection of mouse exploratory behaviour. Behavioural Brain Research 125, 127-132.

Dall, S. R. X., Houston, A. I. \& Mchamara, J. M. (2004). The behavioural ecology of personality: consistent individual differences from an adaptive perspective. Ecology Letters 7, 734739.

Daniewski, W. \& Jezierski, T. (2003). Effectiveness of divergent selection for open-field activity in rabbits and correlated response for body weight and fertility. Behavior Genetics 33, $337-345$

Darwin, C. (1859). The Origin of Species by Means of Natural Selection. John Murray, London.

D'Eath, R. B. \& Burn, C. C. (2002). Individual differences in behaviour: a test of 'coping style' does not predict residentintruder aggressiveness in pigs. Behaviour 139, 1175-1194.

De Boer, S. F., Van Der Vegt, B. J. \& Koolhaas, J. M. (2003). Individual variation in aggression of feral rodent strains: a standard for the genetics of aggression and violence? Behavior Genetics 33, 485-501.

Dellu, F., Contarino, A., Simon, H., Koob, G. F. \& Gold, L. H. (2000). Genetic differences in response to novelty and spatial memory using a two-trial recognition task in mice. Neurobiology of Learning and Memory 73, 31-48.

Diaz-Uriarte, R. (2002). Incorrect analysis of crossover trials in animal behaviour research. Animal Behaviour 63, 815-822. 
Digman, J. M. (1990). Personality structure: Emergence of the fivefactor model. Annual Review of Psychology 41, 417-449.

Dingemanse, N. J., Both, C., Drent, P. J. \& Tinbergen, J. M. (2004). Fitness consequences of avian personalities in a fluctuating environment. Proceedings of the Royal Society of London, Series $B$ 271, 847-852.

Dingemanse, N. J., Both, C., Drent, P. J., Van Oers, K. \& Van NoordwiJk, A. J. (2002). Repeatability and heritability of exploratory behaviour in great tits from the wild. Animal Behaviour 64, 929-938.

Dingemanse, N. J., Both, G., Van Noordwijk, A. J., Rutten, A. L. \& Drent, P. J. 2003. Natal dispersal and personalities in great tits (Parus major). Proceedings of the Royal Society of London, Series B 270, 741-747.

Dingemanse, N. J. \& De Goede, P. (2004). The relation between dominance and exploratory behaviour is context-dependent in wild great tits. Behavioral Ecology 15, 1023-1030.

Dingemanse, N. J. \& RÉale, D. (2005). Natural selection and animal personality. Behaviour. 142, 1159-1184.

Drent, P. J., Van Oers, K. \& Van Noordwijk, A. J. (2003). Realised heritability of personalities in the great tit (Parus major). Proceedings of the Royal Society of London, Series B 270, 45-51.

Eley, T. G. \& Plomin, R. (1997). Genetic analyses of emotionality. Current Opinion in Neurobiology 7, 279-284.

Ellis, B. J. Jackson, J. J. \& Boyce, W. T. (2006). The stress response system: universality and adaptive individual variation. Developmental Review 26, 175-212.

Erhard, H. W., Mendl, M. \& Christiansen, S. B. (1999). Individual difference in tonic immobility may reflect behavioural strategies. Applied Animal Behaviour Science 64, 31-46.

FAIRbanks, L. A. (1996). Individual differences in maternal sytle. Causes and consequences for mothers and offspring. Advances in the Study of Behavior 25, 579-611.

FAIRBAnKs, L. A. (2001). Individual differences in response to a stranger: social impulsivity as a dimension of temperament in vervet monkeys (Cercopithecus aethiops sabaeus). Fournal of Comparative Psychology 115, 22-28.

Fairbanks, L. A., Newman, T. K., Bailey, J. N., Jorgensen, M. J., Breidenthal, S. E., Ophoff, R. A., Comuzzie, A. G., Martin, L. J. \& Rogers, J. (2004). Genetic contributions to social impulsivity and aggressiveness in vervet monkeys. Biological Psychiatry 55, 642-647.

Falconer, D. S. \& Mackay, T. F. C. (1996). Introduction to Quantitative Genetics. $4^{\text {th }}$ edition. Longman, New York.

FAure, J. M. \& Mills, A. D. (1998). Improving the adaptability of animals by selection. In Genetics and the Behaviour of Domestic Animals (ed. T. Grandin), pp. 235-264. Academic Press, San Diego.

Fell, L. R., Colditz, I. G., Walker, K. H. \& Watson, D. L. (1999). Association between temperament, performance and immune function in cattle entering a commercial feedlot. Australian Fournal of Experimental Agriculture 39, 795-802.

Felsenstein, J. (1985). Phylogenies and the comparative method. American Naturalist 125, 1-15.

FILE, S. E. (2001). Factors controlling measures of anxiety and response to novelty in the mouse. Behavioural Brain Research 125, 151-157.

File, S. E. \& Wardill, A. G. (1975). Validity of head-dipping as a measure of exploration in a modified hole-board. Psychopharmacologia 44, 53-59.

FLINT, J. (2003). Analysis of quantitative trait loci that influence animal behavior. Fournal of Neurobiology 54, 46-77.
Fraser, D. F., Gilliam, J. F., Daley, M. J., Le, A. N. \& Skalski, G. T. (2001). Explaining leptokurtic movement distributions: intrapopulation variation in boldness and exploration. American Naturalist 158, 124-135.

FRY, J. D. (1992). The mixed-model analysis of variance applied to quantitative genetics: biological meaning of the parameters. Evolution 46, 540-550.

Garland, T., Jr., Bennet, A. F. \& Rezende E. L. (2005). Phylogenetic approaches in comparative physiology. fournal of experimental Biology 208, 3015-3035.

Garland, T., Jr., Dickerman, A. W., Janis, C. M., \& Jones, J. A. (1993). Phylogenetic analysis of covariance by computer simulation. Systematic Biology 42, 265-292.

Gauly, M., Mathiak, H., Hoffmann, K., Kraus, M. \& Erhardt, G. (2001). Estimating genetic variability in temperamental traits in German Angus and Simmental cattle. Applied Animal Behaviour Science 74, 109-119.

Gerken, M. \& Petersen, J. (1992). Heritabilities for behavioral and production traits in Japanese quail Coturnix coturnix japonica bidirectionally selected for dustbathing activity. Poultry Science 71, 779-788.

Giles, N. \& Huntingford, F. A. (1984). Predation risk and interpopulation variation in anti-predator behaviour in the threespined stickleback Gasterosteus aculeatus L. Animal Behaviour, 32, 264-275.

Glickman, S. E. \& Sroges, R. W. (1966). Curiosity in zoo animals. Behaviour 26, 151-188.

Godin, J.-G. J. \& Dugatkin, L. A. (1996). Female mating preference for bold males in the guppy, Poecilia reticulata. Proceedings of the National Academy of Science USA 93, 10262 10267.

Gosling, S. D. (2001). From mice to men: what can we learn about personality from animal research? Psychological Bulletin 137, 45-86.

Grandin, T. (Ed.). (1998). Genetics and the Behavior of Domestic Animals, Academic Press, San Diego.

Greenberg, R. (1984). Neophobia in the foraging-site selection of a neotropical migrant bird: an experimental study. Proceedings of the National Academy of Science USA 81, 3778-3780.

GreEnberG, R. (1992). Differences in neophobia between naive song and swamp sparrows. Ethology 91, 17-24.

Greenberg, R. (2003). The role of neophobia and neophilia in the development of innovative behavior of birds. In Animal Innovation (eds. S. M. Reader and K. N. Laland), pp. 175-196. Oxford University Press, Oxford.

Greenberg, R. \& Mettke-Hofmann, C. (2001). Ecological aspects of neophobia and neophilia in birds. Current Ornithology 16, 119-178.

Groothuis, T. G. G. \& Carere, C. (2005). Avian personalities: characterization and epigenesis. Neuroscience and Biobehavioral Revieres 29, 137-150.

Hall, C. S. (1934). Emotional behaviour in the rat. I. Defecation and urination as measures of individual differences in emotionality. Fournal of Comparative Psychology 18, 385-403.

Hansen, S. W. \& Møller, S. H. (2001). The application of a temperament test to on-farm selection of mink. Acta Agriculturae Scandinavica, Section A, Animal Science 30, S93-S98.

Hansen, T. F. (1997). Stabilizing selection and the comparative analysis of adaptation. Evolution 51, 1341-1351.

Harvey P. H. \& Pagel M. D. (1991). The Comparative Method in Evolutionary Biology. Oxford University Press, Oxford. 
Hedrick, A. V. (2000). Crickets with extravagant mating songs compensate for predation risk with extra caution. Proceedings of the Royal Society of London, Series B 267, 671-675.

Hedrick, A. V. \& Riechert, S. E. (1989). Genetically-based variation between two spider populations in foraging behavior. Oecologia 80, 533-539.

Heiblum, R., Aizenstein, O., Gvaryahu, G., Voet, H., Robinzon, B., SNAPIR, N. (1998). Tonic immobility and open field responses in domestic fowl chicks during the first week of life. Applied Animal Behaviour Science 60, 347-357.

Henderson, N. D. (1990). Quantitative genetic analysis of neurobehavioral phenotypes. In Developmental Behavior Genetics: Neural, Biometrical, and Evolutionary approaches. (eds. M. E. Hahn et al.), pp. 283-397. Oxford University Press, New-York.

Higley, J. D., Mehlman, P. T., Higley, S. B., Fernald, B., Vickers, J., Lindell, S. G., Taub, D. M., Suomi, S. J. \& LinnolLA, M. (1996). Excessive mortality in young free-ranging male nonhuman primates with low cerebrospinal fluid 5-hydroxyindoleacetic acid concentrations. Archives in General Psychiatry 53, 537-542.

Höjesjö, J., Johnsson, J. I. \& Bohlin, T. (2002). Can laboratory studies on dominance predict fitness of young brown trout in the wild? Behavioural Ecology and Sociobiology 52, 102-108.

Höjesjö, J., Johnsson, J. \& Bohlin, T. (2004). Habitat complexity reduces the growth of aggressive and dominant brown trout (Salmo trutta) relative to subordinates. Behavioural Ecology and Sociobiology 56, 286-289.

Holmes, A., Wrenn, C. C., Harris, A. P., Thayer, K. E. \& Crawley, J. N. (2002). Behavioral profiles of inbred strains on novel olfactory, spatial and emotional tests for reference memory in mice. Genes Brain and Behavior 1, 55-69.

Houle, D. (1992). Comparing evolvability and variability of quantitative traits. Genetics 130, 195-204.

Houtman, A. M. \& Falls, J. B. (1994). Negative assortative mating in the white-throated sparrow, Zonotrichia albicollis, the role of mate choice and intra-sexual competition. Animal Behaviour 48, 377-383.

Hughes, R. N. (1997). Intrinsic exploration in animals: motives and measurement. Behavioural Processes 41, 213-226.

Huntingford, F. A. $(1976 a)$. The relationship between antipredator behaviour and aggression among conspecifics in the three-spined stickleback, Gasterosteus aculeatus. Animal Behaviour, 24, 245-260.

Huntingford, F. A. (1976b). The relationship between inter- and intra-specific aggression. Animal Behaviour 24, 485-497.

Huntingford, F. A. (1982) Do inter- and intra-specific aggression vary in relation to predation pressure in sticklebacks? Animal Behaviour, 30, 909-916.

Huntingford, F. A., Wright, P. J. \& Tierney, J. F. (1994). Adaptive variation in antipredator behaviour in threespine stickleback. In The Evolutionary Biology of the Threespine Stickleback (eds. M. A. Bell and S. A. Foster), pp. 345-380. Oxford University Press, New York.

Iguchi. K., Matsubara, N. \& Hakoyama H. (2001). Behavioural individuality assesed from two strains of cloned fish. Animal Behaviour 61, 351-356.

Johnston, T. D. \& Edwards, L. (2002). Genes, interactions, and the development of behavior. Psychological Review 109, 26-34.

Jones, B. R. (1982). Experimental novelty and tonic immobility in chickens (Gallus domesticus). Behavioural Processes 9, 255-260.

Jones, B. R., Mills, A. D. \& Faure, J. (1991). Genetic and experiential manipulation of fear-related behavior in Japanese quail chicks (Coturnix coturnix japonica). Fournal of Comparative Psychology 105, 15-24.

Kagan, J., Reznick, J. S. \& Snidman, N. (1988). Biological bases of childhood shyness. Science 240, 167-171.

Kagan, J. \& Snidman, N. (2004). The Long Shadow of Temperament. Harvard University Press.

Kamil, A. C. (1994). A synthetic approach to the study of animal intelligence. In Behavioural Mechanisms in Evolutionary Ecology (ed. L. A. Real), pp. 11-45. University of Chicago Press, Chicago.

Kenttämies, H., Valberg Nordrum, N., Brenøe, U. T., Smeds, K., Johannessen, K. R. \& Bakken, M. (2002). Selection for more confident foxes in Finland and Norway: heritability and selection response for confident behaviour in blue foxes (Alopex lagopus). Applied Animal Behaviour Science 78, 67-82.

Ketterson, E. D. \& Nolan, V. (1999). Adaptation, exaptation, and constraint: A hormonal perspective. American Naturalist 154, S4-S25.

Kilgour, R. J. \& Szantar-Coddington, M. R. (1995). Arena behaviour of ewes selected for superior mothering ability differs from that of unselected ewes. Animal Reproduction Science 37, 133141.

Kingsolver, J. G., Hoekstra, H. E., Hoekstra, J. M., Berrigan, D., Vignieri, S. N., Hill, C. E., Hoang, A., Gilbert, P. \& Beerli, P. (2001). The strength of phenotypic selection in natural populations. American Naturalist 157, 245-261.

Klotchkov, D. V., Trapezov, O. V. \& Kharlamova, A. V. (1998). Folliculogenesis, onset of puberty and fecundity of mink (Mustela vison Schreb.) selectively bred for docility or aggressiveness. Theriogenology 49, 1545-1553.

Knapton, R. W. \& Falls, J. B. (1983). Differences in parental contribution among pair types in the polymorphic Whitethroated sparrow. Canadian fournal of Zoology 61, 1288-1292.

Koolhans, J. M., De Boer, S. F. \& Bohus, B. (1997). Motivational systems or motivational states: Behavioural and physiological evidence. Applied Animal Behavior Science 53, 131143.

Koolhaas, J. M., Korte, S. M., De Boer, S. F., Van Der Vegt, B. J., Van Reenen, G. G., Hopster, H., De Jong, I. C., Ruis, M. A. W. \& Blokhuis, H. J. (1999). Coping style in animals: current status in behavior and stress-physiology. Neuroscience and Biobehavioral Review 23, 925-935.

Koops, M. A. \& Giraldeau, L. (1996). Producer-scrounger foraging games in starlings: a test of rate-maximizing and risksensitive models. Animal Behaviour 51, 773-783.

KRACKOw, S. (2003). Motivational and heritable determinants of dispersal latency in wild male house mice (Mus musculus musculus). Ethology 109, 671-689.

KRUUK, L. E. B. (2004). Estimating genetic parameters in natural populations using the 'animal model'. Philosophical Transactions of the Royal Society of London Series B 359, 873-890.

LANDE, R. (1979). Quantitative genetics analysis of multivariate evolution, applied to brain:body size allometry. Evolution 33, $402-416$

Lande, R. \& ARnold, S. J. (1983). The measurement of selection on correlated characters. Evolution 37, 1210-1226.

Le Neindre, P., Boivin, X. \& Boissy, A. (1996). Handling of extensively kept animals. Applied Animal Behaviour Science, 49, 7381.

LI, C. C. (1975). Path Analysis - a Primer. Boxwood Press, California.

Libersat, F. \& Pflueger, H. J. (2004). Monoamines and the orchestration of behaviour. Bioscience 54, 17-25. 
Losos, J. B. \& Miles, D. B. (1994). Adaptation, constraint and the comparative method: phylogenetic issues and methods. In: Ecological Morphology: Integrative Organismal Biology (Eds. P. C. Wainwright and S. M. Reilly), pp. 240-302. The University of Chicago Press, Chicago.

Lowe, S. E. \& Bradshaw, J. W. S. (2001). Ontogeny of individuality in the domestic cat in the home environment. Animal Behaviour 61, 231-237.

Lynch, M. \& Walsh, B. (1998). Genetics and Analysis of Quantitative Traits, Sinauer Associates.

Maestripieri, D. (1993). Maternal anxiety in rhesus macaques (Macaca mulatta) II. Emotional bases of individual differences in mothering style. Ethology 95, 32-42.

Maestripieri, D. (1998). Parenting styles of abusive mothers in group-living rhesus macaques. Animal Behaviour 55, 1-11.

Maestripieri, D., Tomaszycki, M. \& Carroll, K. A. (1999). Consistency and change in the behavior of rhesus macaque abusive mothers with successive infants. Developmental Psychobiology 34, 29-35.

Magurran, A. E. (1993). Individual differences and alternative behaviours. In: Behaviour of Teleost Fishes (ed. T. J. Pitcher), pp. 441-477, Chapman \& Hall, New York.

Maier, S. E., Vandenhoff, P. \& Crowne, D. P. (1988). Multivariate analysis of putative measures of activity, exploration, emotionality, and spatial behavior in the hooded rat (Rattus norvegicus). Fournal of Comparative Psychology 102, 378387.

Malmkvist, J., \& Hansen, S. W. (2001). The welfare of farmed mink (Mustela vison) in relation to behavioural selection: a review. Animal Welfare 10, 41-52.

Malmkvist, J., Houbak, B. \& Hansen, S. W. (1997). Mating time and litter size in farm mink selected for confident or timid behaviour. Animal Science 65, 521-525.

Marchetti, C. \& Drent, P. J. (2000). Individual differences in the use of social information in foraging by captive great tits. Animal Behaviour 60, 131-140.

Markowitz, T. M., Dally, M. R., Gursky, K. \& Price E. O. (1998). Early handling increases lamb affinity for humans. Animal Behaviour 55, 573-587.

Marples, N. M., Roper, T. J., \& Harper, D. G. C. (2003). Responses of wild birds to novel prey: evidence of dietary conservatism. Oikos 83, 161-165.

Martin, P. (1998). The Sickening Mind. Harper Collins, London.

Martins, E. P. \& Hansen, T. F. (1997). Phylogenies and the comparative method: a general approach to incorporating phylogenetic information into the analysis of interspecific data. American Naturalist 149, 646-667.

Mcdougall, P. T., Réale, D., Sol, D. \& Reader, S. M. (2006). Wildlife conservation and animal temperament: an evolutionary overview. Animal Conservation, 9, 39-48.

Mehlman, P. T., Higley, J. D., Faucher, I., Lilly, A. A., Taub, D. M., Vickers, J., Suomi, S. J. \& Linnoila, M. (1994). Low CSF 5-HIAA concentration and severe aggression and impaired impulse control in nonhuman primates. American fournal of Psychiatry 151, 1485-1491.

Mehlman, P. T., Higley, J. D., Faucher, I., Lilly, A. A., Taub, D. M., Vickers, J., Suomi, S. J. \& Linnoila, M. (1995). Correlation of CSF 5-HIAA concentration with sociality and the timing of emigration in free-ranging primates. American fournal of Psychiatry 152, 907-913.

Mehlman, P. T., Higley, J. D., Fernald, B. J., Sallee, F. R., Suomi, S. J. \& Linnolla, M. (1997). CSF 5-HIAA, testosterone, and sociosexual behaviors in free-ranging male rhesus macaques in the mating season. Psychiatry Research 72, 89-102.

Merilä, J. \& Sheldon, B. C. (1999). Genetic architecture of fitness and nonfitness traits: empirical patterns and development of ideas. Heredity. 83, 103-109.

Mettke-Hofmann, G., Wink, M., Winkler, H. \& Leisler, B. (2004). Exploration of environmental changes related to lifestyle. Behavioral Ecology 16, 247-254.

Mettke-Hofmann, C., Winkler, H. \& Leisler, B. (2002). The significance of ecological factors for exploration and neophobia in parrots. Ethology 108, 249-272.

MiczeK, K. A., Fish, E. W., De Bold, J. F. \& De Almeida, R. M. M. (2002). Social and neural determinants of aggressive behavior : pharmacotherapeutic targets at serotonin, dopamin, and $\gamma$-aminobutyric acid system. Psychopharmacology 163, 434 458.

Mills, A. D. \& Faure, J. M. (2000). Ease of capture in lines of Japanese quail (Coturnix japonica) subjected to contrasting selection for fear or sociability. Applied Animal Behaviour Science 69, 125-134.

Morris, G. A., Gullen, N. G., Kilgour, R. \& Bremner, K. J. (1994). Some genetic factors affecting temperament in Bos Taurus cattle. New Zealand Fournal of Agricultural Research 37, 167-175.

Mousseau, T. A. \& Roff, D. A. (1989). Natural selection and the heritability of fitness components. Heredity 59, 181-197.

Mousseau, T. H., Sinervo, B. \& Endler J. A. (2000). Adaptive Genetic Variation in the Wild. Oxford University Press, New York.

Nelson, R. J. \& Chiavegatto, S. (2001). Molecular basis of aggression. Trends in Neurosciences. 12, 713-719.

O'Steen, S., Cullum, A. J. \& Bennett, A. F. (2002). Rapid evolution of escape ability in Trinidadian guppies (Poecillia reticulata). Evolution 56, 776-784.

OXFORD DICTIONARY OF ENGLISH (2005). Revised edn. (Ed. C. Soanes and A. Stevenson). Oxford University Press, Oxford.

Perdeck, A. C., Visser, M. E. \& Balen, J. H. v. (2000). Great tit Parus major survival and the beech-crop cycle. Ardea 88, 99-106.

Pfeffer, K., Fritz, J. \& Kotrschal, K. (2002). Hormonal correlates of being an innovative greylag goose, Anser anser. Animal Behaviour 63, 687-695.

Pickering, A. D. \& Gray, J. A. (1990). The neuroscience of personality. In: Handbook of Personality: Theory and Research, $2 n d$ edn. (Ed. L. A. Pervin and O. P. John), pp. 277-299. The Guilford Press, New York.

Plomin, R. \& Caspi, A. (1999). Behavioral genetics and personality. In: Handbook of Personality: Theory and Research, 2nd edn. (Ed. L. A. Pervin and O. P. John), pp. 251-276. The Guilford Press, New York.

Plusquellec, P., Bouissou M. F. \& Le Pape, G. (2001). Early predictors of dominance ability in heifers (Bos taurus, L.) of the Herens breed. Behaviour 138, 1009-1031.

Price, E. O. (1999). Behavioral development in animals undergoing domestication. Applied Animal Behaviour Science 65, 245-271.

Raleigh, M. J., Mcguire, M. T., Brammer, G. L., Pollack, D. B. \& Yuwiler, A. (1991). Serotonergic mechanisms promote dominance acquisition in adult male vervet monkeys. Brain Research 559, 181-190.

Rauw, W. M., Luiting, P., Bakken, M., Schuurman, T., De Veer C. J. M, \& VAngen, O. (2000). Behavioural differences in nonreproductive adult females in a long-term selection experiment for litter size in mice. Applied Animal Behaviour Science 66, 249-262. 
Reader, S. M. (2006). Evo-devo, modularity, and evolvability: insights for cultural evolution. Behavioral and Brain Sciences 29, 361-362.

Reader, S. M. \& Laland, K. N. (2003). Animal innovation: an introduction. In Animal Innovation (eds. S. M. Reader \& K. N. Laland), pp. 3-35. Oxford University Press, Oxford.

Réale, D. \& Festa-Bianchet, M. (2003). Predator-induced selection on temperament in bighorn ewes. Animal Behaviour 65, 463-470.

Réale, D., Festa-Bianchet, M. \& Jorgenson, J. T. (1999). Heritability of body mass varies with age and season in wild bighorn sheep. Heredity 83, 526-532.

Réale, D., Gallant, B. Y., Leblanc, M. \& Festa-Bianchet, M. (2000). Consistency of temperament in bighorn ewes and correlates with behaviour and life history. Animal Behaviour 60, 589-597.

ReIf, A. \& LESCH, K.-P. (2003). Toward a molecular architecture of personality. Behavioural Brain Research 139, 1-20.

Renner, M. J. (1990). Neglected aspects of exploratory and investigatory behaviour. Psychobiology 18, 16-22.

Reznick, D. \& Travis, J. (2003). Adaptation. In Evolutionary Ecology: Concept and Case Studies (eds. C. W. Fox, D. A. Roff and D. J. Fairbairn), pp. 44-57. Oxford University Press, Oxford.

Richardson, J. M. L. (2001). A comparative study of activity levels in larval anurans and response to the presence of different predators. Behavioral Ecology 12, 51-58.

Riechert, S. E. \& HaLL, R. F. (2000). Local population success in heterogeneous habitats: reciprocal transplant experiments completed on a desert spider. Fournal of Evolutionary Biology 13, 541-550.

Riechert, S. E. \& Hedrick, A. V. (1993). A test for correlations among fitness-linked behavioural traits in the spider Agelenopsis aperta (Araneae, Agelenidae). Animal Behaviour 46, 669-675.

Riechert, S. E. \& MaYnard Smith J. (1989). Genetic analyses of two behavioural traits linked to individual fitness in the desert spider, Agelenopsis aperta. Animal Behaviour 37, 624-637.

Roff, D. A. (1997). Evolutionary Quantitative Genetics, Chapman \& Hall.

Roff, D. A. (2002). Life History Evolution. Sinauer Associates Inc., Sunderland.

Roff, D. A., Crnokrak, P. \& Fairbairn, D. J. (2003). The evolution of trade-offs: geographic variation in call duration and flight ability in the sand cricket, Gryllus firmus. Fournal of Evolutionary Biology 16, 744-753.

Russell, P. A. (1983). Psychological studies of exploration in animals: a reappraisal. In Exploration in Animals and Humans (eds. J. Archer and L. I. A. Birke), pp. 22-54. Van Nostrand Rheinhold, Wokingham.

Schaeffer, L. R. (2004). Application of random regression models in animal breeding. Livestock Production Science 86, 35-45.

Scheiner, S. M., Mitchell, R. J. \& Callahan, H. S. (2000). Using path analysis to measure natural selection. Fournal of Evolutionary Biology 13, 423-433.

Schwabl, H. (1993). Yolk is a source of maternal testosterone for developing birds. Proceedings of the National Academy of Science USA 90, 11446-11450.

Seferta, A., Guay, P. J., Marzinotto, E. \& Lefebvre, L. (2001). Learning differences between feral pigeons and zenaida doves: The role of neophobia and human proximity. Ethology 107, 281293.

Shipley, B. (2000). Cause and Correlation in Biology: a User's Guide to Path Analysis, Structural Equations and Causal Inference. Cambridge University Press.
Sih, A., Bell, A. M., \& Johnson, J. C. (2004a). Behavioral syndromes: an ecological and evolutionary overview. Trends in Ecology and Evolution 19, 372-378.

Sin, A., Bell, A. M., Johnson, J. C. \& Ziemba, R. E. (2004b). Behavioral syndromes: an integrative overview. Quarterly Review of Biology 79, 2410-277.

Sinn, D. L., Apiolaza, L. A. \& Moltschaniwskyj, N. A. (2006). Heritability and fitness-related consequences of squid personality traits. Fournal of Evolutionary Biology 19, 1437-1447.

Spoolder, H. A., J. A. Burbidge, A. B. Lawrence, P. H. Simmins \& EDWARDS, S. A. (1996). Individual behavioural differences in pigs: Intra- and inter-test consistency. Applied Animal Behaviour Science 49, 185-98.

Stamps, J. A. (1991). Why evolutionary issues are reviving interest in proximate behavioral mechanism. American Zoologist 31, 333-348.

Stirling, D. G., Réale, D. \& Roff, D. A. (2002). Selection, structure and the heritability of behaviour. Fournal of Evolutionary Biology 15, 277-289.

Sundström, L. F., Petersson, E., Höjesjö, J., Johnsson, J. I. \& JARVI, T. (2004). Hatchery selection promotes boldness in newly hatched brown trout (Salmo trutta): implications for dominance. Behavioral Ecology, 15, 192-198.

Trut, L. N. (1999). Early canid domestication: the farm-fox experiment. American Scientist 87, 160-169.

Van Oers, K., De Jong, G., Drent, P. J. \& Van Noordwijk, A. J. (2004a). Genetic correlations of avian personality traits: Correlated response to artificial selection. Behavior Genetics 34, 611-619.

Van Oers, K., Drent, P. J., De Goede, P. \& Van Noordwijk, A. J. $(2004 b)$. Realized heritability and repeatability of risk-taking behaviour in relation to avian personality. Proceedings of the Royal Society of London Series B 271, 65-73.

Van Oers, K., Drent, P. J., De Jong, G. \& Van Noordwijk, A. J. $(2004 c)$. Additive and nonadditive genetic variation in avian personality traits. Heredity 93, 496-503.

Verbeek, M. E. M., Boon, A. \& Drent, P. J. (1996). Exploration, aggressive behaviour and dominance in pair-wise confrontations of juvenile male great tits. Behaviour 133, 945-963.

Verbeek, M. E. M., De Goede, P., Drent, P. J. \& Wiepkema, P. R. (1999). Individual behavioural characteristics and dominance in aviary groups of great tits. Behaviour 136, 23-48.

Verbeek, M. E. M., Drent, P. J. \& Wiepkema, P. R. (1994). Consistent individual differences in early exploratory behaviour of male great tits. Animal Behaviour 48, 1113-1121.

VIA, S. \& LANDE, R. (1985). Genotype-environment interaction and the evolution of phenotypic plasticity. Evolution 39, 505523.

Voisinet, B. D., Grandin, T., Tatum, J. D., O’Connor, S. F. \& Struthers, J. J. (1997). Feedlot cattle with calm temperaments have higher average daily gains than with excitable temperaments. Journal of Animal Science 75, 892-892.

Ward, A. J. W., Thomas, P., Hart, P. J. B. \& Krause, J. (2004). Correlates of boldness in three-spined sticklebacks (Gasterosteus aculeatus). Behavioural Ecology and Sociobiology, 55, 561-568.

Wagner, G. P. (1996). Homologues, natural kinds and the evolution of modularity. American Zoologist 36, 36-43.

Wagner, G. P. (2001). The Character Concept in Evolutionary Biology. Academic Press, San Diego. CA.

Wahlsten, D. (2001). Standardizing tests of mouse behavior: reasons, recommendations and reality. Physiology and Behavior 73, 695-704. 
Webster, S. J. \& Lefebvre, L. (2001). Problem solving and neophobia in a columbiform-passeriform assemblage in Barbados. Animal Behaviour 62, 23-32.

Westerberg, M., Staffan, F. \& Magnhagen, C. (2004). Influence of predation risk on individual competitive ability and growth in Eurasian perch, Perca fluviatilis. Animal Behaviour 67, 273-279.

Westergando, G. C., Gleveland, A., Trenkle, M. K., Lussier, I. D. \& Higley, J. D. (2003a). CSF 5-HIAA concentration as an early screening tool for predicting significant life history outcomes in female specific-pathogen-free (SPF) rhesus macaques (Macaca mulatta). Fournal of Medical Primatology 32, 95-104.

Westergaard, G. C., Suomi, S. J., Chavanne, T. J., Houser, L., Hurley, A., Gleveland, A., Snoy, P. J. \& Higley, J. D. (2003b). Physiological correlates of aggression and impulsivity in freeranging female primates. Neuropsychopharmacology 28, 10451055.

Westergand, G. C., Suomi, S. J., Higley, J. D. \& Mehlman, P. T. (1999). CSF 5-HIAA and aggression in female macaque monkeys: species and interindividual differences. Psychopharmacology. 146, 440-446.
Whitlock, M. C., Phillips, P. C. \& Fowler, K. (2002). Persistent changes in the genetic covariance matrix after a bottleneck. Evolution 56, 1968-1975.

Wielebnowski, N. C. \& Brown, J. L. (1998). Behavioral correlates of physiological estrus in cheetahs. Zoo Biology 17, 193-209.

Wilson, D. S. (1994). Adaptive genetic-variation and human evolutionary psychology. Ethology and Sociobiology 15, 219-235.

Wilson, D. S. (1998). Adaptive individual differences within single populations. Philosophical Transactions of the Royal Society of London Series B 353, 199-205.

Wilson, D. S., Glark, A. B., Coleman, K. \& Dearstyne, T. (1994). Shyness and boldness in humans and other animals. Trends in Ecology \& Evolution 9, 442-446.

Wilson, D. S. \& Yoshimura, J. (1994). On the coexistence of specialists versus generalists. The American Naturalist 144, 692-707.

Wilson, R. C., Vacek, T., Lanier, D. L. \& Dewsbury, D. A. (1976). Open-field behavior in muroid rodents. Behavioral Biology 17, 495-506.

Winter, D. G. \& Barenbaum, N. B. (1999). History of modern personality theory and research. In: Handbook of Personality: Theory and Research, 2nd edn. (eds. L. A. Pervin and O. P. John), pp. 3-27. The Guilford Press, New York. 